\title{
Tribological behavior of nanocarbon materials with different dimensions in aqueous systems
}

\author{
Hongmei YANG, Jiusheng LI $^{*}$, Xiangqiong ZENG* \\ Chinese Academy of Sciences, Shanghai 201210, China \\ Received: 02 November 2017 / Revised: 08 April 2018 / Accepted: 24 July 2018 \\ (C) The author(s) 2018. This article is published with open access at Springerlink.com
}

Laboratory for Advanced Lubricating Materials, Shanghai Advanced Research Institute, Chinese Academy of Sciences, University of

\begin{abstract}
Due to the widespread use of nanocarbon materials (NCMs), more researchers are studying their tribological performances. In this work, the tribological behaviors of the following five types of NCMs with different geometric shapes were evaluated in a novel oil-in-water system: spherical fullerenes (C60, 0D), tubular multi-walled carbon nanotubes (MWCNT, 1D), sheet graphene oxide (GO, 2D), sheet graphene oxide derivative (Oct-O-GO, 2D), and lamellar graphite (G, 3D). Among these, GO with two types of oxidation degrees, i.e., GO(1), $\mathrm{GO}(2)$, and Oct-O-GO(1) were synthesized and characterized using Fourier-transform infrared spectroscopy, Raman spectroscopy, x-ray diffraction, thermogravimetric analysis, scanning electron microscopy, and contact angle measurements. The load-carrying capacity of the NCM emulsions were evaluated using a four-ball test machine, and the lubrication performances were investigated using a high-frequency reciprocating friction and wear tester with a sliding distance of $1,800 \mathrm{~mm}$ under different loads ( $50 \mathrm{~N}$ and $100 \mathrm{~N}$ ) at $0.5 \mathrm{~Hz}$. The results revealed that the Oct-O-GO(1) emulsion exhibited the best load-carrying capacity, and the best friction-reducing and anti-wear properties compared to other emulsions. Moreover, the anti-wear advantage was more prominent under high load conditions, whereas the other emulsions exhibited a certain degree of abrasive or adhesive wear. The lubrication mechanism was determined through the analysis of worn surfaces using scanning electron microscopy/energy-dispersive x-ray spectroscopy, micro-Raman spectroscopy, and x-ray photoelectron spectroscopy. The results revealed that during frictional sliding, the ingredients in the emulsion can absorb and react with the freshly exposed metal surface to form surface-active films to protect the surfaces from abrasion. Moreover, it was found that the higher the amount of ingredients that contain alkyl and $\mathrm{O}-\mathrm{H} / \mathrm{C}=\mathrm{O}$, the better was the lubrication performance in addition to an increase in the carbon residue in the tribofilm generated on the meal surface.
\end{abstract}

Keywords: nano-carbon materials; tribological behavior; modified graphene oxide; oil-in-water emulsion

\section{Introduction}

Graphene has attracted significant attention in recent years. One of its most desirable properties is its superlow-friction characteristic, which expands the concept of zero wear [1-4]. Other nanocarbon materials (NCMs) with the same skeleton structures, such as fullerene (C60), multi-walled carbon nanotubes (MWCNTs), graphite (G) and graphene oxide (GO) also exhibit remarkably low friction and wear [5-9]; thus, they demonstrate a high potential for application as lubricant additives.

Moreover, C60 has been applied to lubricant oil, ionic liquids[10, 11], solid films [8] and other solutions [12-14] (i.e., ethanol and water, etc.) to study their tribological properties. Lei et al. reported that when $0.5 \mathrm{wt}$.\% of fullerene-styrene sulfonic acid copolymer was added to base stock, it exhibited the maximum

* Corresponding authors: Jiusheng LI, E-mail: lijs@sari.ac.cn; Xiangqiong ZENG, E-mail: zengxq@sari.ac.cn 
$P_{\mathrm{B}}$ value and minimum wear scar diameter (WSD) [14]. When used as oil additives, alkylated C60 exhibits a remarkable anti-wear property by reducing the areas of the worn surfaces and smoothing the scuffing. Liu et al. applied alkylated C60 to paraffin oil [15]. The results revealed that the addition of the alkylated C60 reduces the friction coefficient both at $25^{\circ} \mathrm{C}$ and $90{ }^{\circ} \mathrm{C}$, where it exists as aggregates and monomers, respectively. This can be attributed to the presence of the aliphatic chains, thus leading to an improved solubility and dispersibility of the target compound in lubricating oils.

Huang et al. utilized MWCNT/minimum quantity lubrication (MQL) in the milling of SKD11 die steel as a cutting fluid [16], which can effectively prevent tool wear, due to the increased wear resistance yielded by the carbon nanotubes, thus increasing the tool-life. Moreover, it allows for a lower cutting temperature environment, resulting in the superior thermal conductivity of MWCNTs [17]. A 1.0 wt.\% addition of MWCNTs can improve the anti-wear, friction coefficient (COF), and load-carrying capacity of the base lubricant when used in Mobilgear 627 and paraffinic mineral oils [18]. The results of the morphology analyses revealed that the addition of MWCNT nanoparticles decreases wear, resulting in a relatively smooth surface with fewer scars, thus indicating that the presence of the MWCNTs significantly reduces metal contact. The mechanism of anti-wear is attributed to the deposition of MWCNT nanoparticles on the worn surface, which may decrease the shearing stress, thus improving the tribological properties [19].

As a conventional solid lubricant, graphite has been extensively studied and applied in industry for more than 40 years [20,21]. It was reported that graphitic tribofilms can form in vivo on the rubbing surfaces of metal-on-metal hip replacements, which are made of cobalt, chrome, and molybdenum [22]. Moreover, Erdemir et al. found that carbon-based tribofilms with catalytically active $\mathrm{MoN}_{x}$-Cu coatings enable base oils (PAO10 and all formulated 5W30) to provide solid tribofilms that protect sliding surfaces against friction and wear [23].

Graphene oxide (GO) is regarded as the precursor in the production of graphene (reduced GO) by chemical and thermal reduction, due to its abundant oxygen-based groups [24]. Moreover, not only can it be obtained easily from the oxidation of graphite, but it can also be readily exfoliated to nanosheets using ultrasonic devices. In recent times, several GO derivatives such as GO-based composites [25, 26], GO-based coating [27, 28], thin films [29], and GO-based nanoparticles have emerged as functional materials for lubrication applications [30-33]. Cheng et al. reported that when using $0.02 \mathrm{wt} . \%$ MGO in base oil, the COF and WSD decreased to approximately $38.4 \%$ and $42.0 \%$, respectively [34]. Moreover, $\mathrm{He}$ et al. found that 0.06 wt.\% GO suspensions can reduce the COF by $37 \%$ and WSD by $19.1 \%$, when compared with water [35]. It was also reported that GO aqueous dispersion can reduce friction between diamond-like carbon and stainless steel. When the GO concentration was increased from 0 to $1.0 \mathrm{wt} . \%$, there was a continuous decrease in the COF from 0.14 to 0.06 [30].

In summary, graphene-based additives in the lubrication medium can effectively reduce the friction and improve the wear resistance of the contacting surfaces [36-38]. However, the abovementioned researches that considered carbon materials as lubricating additives mostly focused on single carbon materials or their composites instead of systematically comparing the tribological behaviors of different carbon materials. To address this, in this study, the tribological behaviors of five types of NCMs with different dimensions, i.e., zero-dimensional C60, one-dimensional MWCNT, twodimensional (2D) GO, n-Octanol modified graphene oxide (Oct-O-GO), and three-dimensional (3D) graphite were investigated. A simple and low-cost chemical method was used to prepare n-Octanol functionalized graphene oxide. Given that the hydrophilicity of different NCMs are different, it is difficult to disperse them in the same solvent. To solve this problem, a novel oil-in-water $(\mathrm{O} / \mathrm{W})$ emulsion system was designed to incorporate the different NCMs in the same system, to obtain stable NCM lubricants. The corresponding tribological properties were then evaluated, and the worn surfaces were analyzed to clarify their lubricating mechanisms.

\section{Experiment}

\subsection{Materials}

The following materials were used as received: flake 
graphite (500 mesh, J\&K Scientific Ltd., 99\%); fullerene (C60, Aldrich, 98\%); muti-walled carbon nanotubes (MWCNT, J\&K Scientific Ltd., 95\%); n-Octanol (Sinopharm Chemical Reagent Co. Ltd., 98\%); thionyl chloride $\left(\mathrm{SOCl}_{2}\right.$, Sinopharm Chemical Reagent Co. Ltd., 96\%); methyl formamide (DMF, Sinopharm Chemical Reagent Co. Ltd., 98\%); dimethylsulfoxide (DMSO, Sinopharm Chemical Reagent Co. Ltd., 98\%); hydrochloric acid $(\mathrm{HCl}$, Sinopharm Chemical Reagent Co. Ltd., 35\%); sulphuric acid $\left(\mathrm{H}_{2} \mathrm{SO}_{4}\right.$, Sinopharm Chemical Reagent Co., Ltd., 98\%); phosphoric acid $\left(\mathrm{H}_{3} \mathrm{PO}_{4}\right.$, Sinopharm Chemical Reagent Co., Ltd., $85 \%$; potassium permanganate $\left(\mathrm{KMnO}_{4}\right.$, Sinopharm Chemical Reagent Co., Ltd., 98\%); hydrogen peroxide $\left(\mathrm{H}_{2} \mathrm{O}_{2}\right.$, Sinopharm Chemical Reagent Co., Ltd., 30\% w/w); Tween 20 (TW 20, Haian petrochemical, 99\%); Carbomer 20 (U 20, Guangzhou Shi Ming Chemical Co., Ltd., 98\%); Methocel ${ }^{\mathrm{TM}}$ 40-202 (Shanghai Qianfei Chemical Co., Ltd., 99\%); poly $\alpha$-olefins (PAO8, Shanghai Naco Lubrication Technology Co., Ltd., 98\%); triethanolamine (TEA, Sinopharm Chemical Reagent Co., Ltd., 97\%). The water used was Wow Haha pure water.

\subsection{Synthesis of GO and Oct-O-GO}

Graphene oxide was prepared from flake graphite using the modified Hummers method [39], due to the advantages of a short reaction time, high oxidation degree, less environmental pollution, and high security. For GO synthesis, a 9:1 mixture of concentrated $\mathrm{H}_{2} \mathrm{SO}_{4} / \mathrm{H}_{3} \mathrm{PO}_{4}(400 \mathrm{~mL})$ was added to a round bottom flask with graphite powder ( $3.0 \mathrm{~g})$ under ice-cold conditions. Thereafter, $\mathrm{KMnO}_{4}(18.0 \mathrm{~g})$ was slowly added to the mixture and stirred at a low speed. After all the $\mathrm{KMnO}_{4}$ was added, the mixture was heated to $50{ }^{\circ} \mathrm{C}$ and stirred for $12 \mathrm{~h}$. The mixture was then cooled to room temperature and poured into $800 \mathrm{~mL}$ ice water with $30 \% \mathrm{H}_{2} \mathrm{O}_{2}(\sim 6 \mathrm{~mL})$ and left for one night. The resultant product was centrifuged, and the supernatant was decanted. The remaining slurry mixture was washed using $400 \mathrm{~mL}$ of pure water followed by $200 \mathrm{~mL}$ of $37 \% \mathrm{HCl}$. The solution was washed using water, and centrifuged until the $\mathrm{pH}$ value of the supernatant was 7. It was then dried in a vacuum oven at $45^{\circ} \mathrm{C}$ to obtain graphite oxide powder. After ultrasonication, the graphene oxide was obtained and labeled as $\mathrm{GO}(1)$. In this study, a higher oxidation degree graphene oxide
$\mathrm{GO}(2)$ was also synthesized according to the steps above by changing the amount of $\mathrm{KMnO}_{4}$ to $12 \mathrm{~g}$ [40].

To prepare Oct-O-GO(1) [41], $200 \mathrm{mg}$ of GO(1) powder was dispersed in a 20:1 mixture of $\mathrm{SOCl}_{2} / \mathrm{DMF}$ $(64 \mathrm{~mL})$ by ultrasonication for $30 \mathrm{~min}$. The solution was then heated under $70{ }^{\circ} \mathrm{C}$ for $24 \mathrm{~h}$ in the sealing tube. After the completion of the reaction, the precipitate was filtered, washed with water and methanol, then dried in a vacuum oven at $45^{\circ} \mathrm{C}$ for $18 \mathrm{~h}$ to obtain $\mathrm{GOCl}(1)$ powder. In the next step, $\mathrm{GOCl}(1)$ was dispersed in $20 \mathrm{~mL}$ of dimethyl sulfoxide (DMSO) after ultrasonication for $0.5 \mathrm{~h}$, and $\mathrm{n}$-Octanol $(7.1 \mathrm{~mL})$ was dropped into the dispersion. The solution was then heated at $80^{\circ} \mathrm{C}$ for $23 \mathrm{~h}$ (monitored by GC). Thereafter, the precipitate was filtered, washed, and dried in the vacuum oven at $60{ }^{\circ} \mathrm{C}$ for $24 \mathrm{~h}$. The n-Octanol modified graphene oxide, i.e., Oct-O-GO(1) powder, was then obtained. The synthesis route is presented in Scheme 1.

\subsection{Preparation of tribological study samples in aqueous systems}

To prepare the $\mathrm{O} / \mathrm{W}$ emulsion system, the NCMs were separately added to a $500 \mathrm{~mL}$ beaker with U20 and Methocel40-202 in water, and stirred at $50{ }^{\circ} \mathrm{C}$ for $10 \mathrm{~min}$. The oil phase (PAO8 and TW20) was then added to the water phase with stirring at $800 \mathrm{rpm}$ for $30 \mathrm{~min}$. Thereafter, triethanolamine was used to adjust the $\mathrm{pH}$ of the emulsion to 7 , and the emulsion was cooled to room temperature with stirring. The formulation of the emulsions is presented in Table 1 .

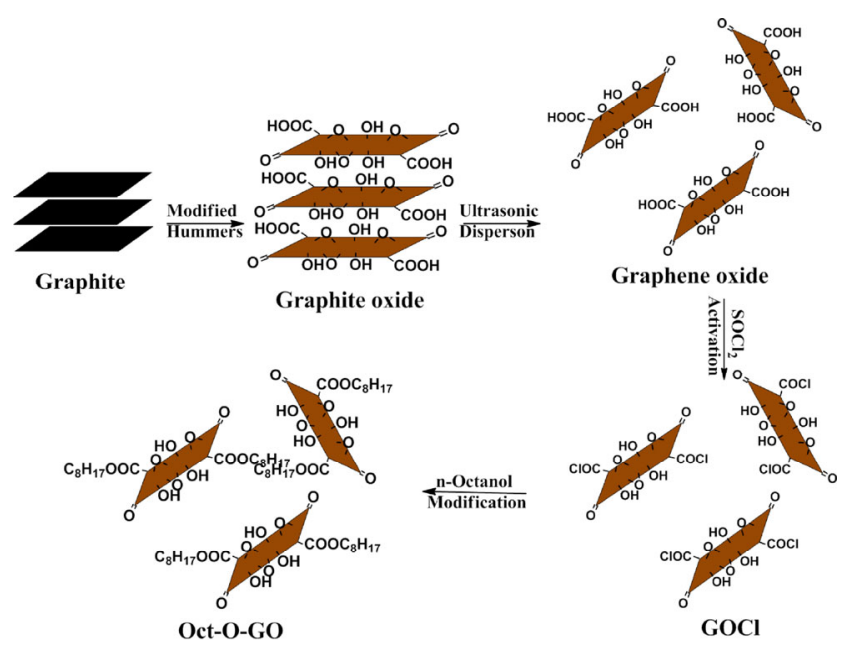

Scheme 1 Synthetic route of GO and Oct-O-GO. 
Table 1 The formulation of the emulsions.

\begin{tabular}{|c|c|c|}
\hline Trade name & Description & $\begin{array}{l}\text { Content } \\
\text { (wt.) }\end{array}$ \\
\hline NCMs & Nano carbon materials & $100 \mathrm{ppm}$ \\
\hline U20 & $\begin{array}{l}\text { Acrylates/C10-30 alkyl acrylate } \\
\text { crosspolymer }\end{array}$ & $0.15 \%$ \\
\hline $\begin{array}{l}\text { Methocel }^{\mathrm{TM}} \\
40-202\end{array}$ & Hydroxypropyl methyl cellulose & $0.50 \%$ \\
\hline $\mathrm{H}_{2} \mathrm{O}$ & Pure water & $92.35 \%$ \\
\hline TW20 & $\begin{array}{l}\text { Polyoxyethylene (20) sorbaitan } \\
\text { monolaurate }\end{array}$ & $4.00 \%$ \\
\hline PAO8 & Hydrogenated polydecene & $3.00 \%$ \\
\hline TEA & Triethylamine & q. s. \\
\hline
\end{tabular}

Moreover, emulsions without any NCMs were selected as the base sample for comparison with those containing NCMs. Images of the emulsions are presented in Fig. 1.

\subsection{Characterization}

The FTIR spectra were obtained by a Paragon 1000 FTIR spectroscope (Perkin Elmer, Inc., USA) with the attenuated total reflectance (ATR) attachment scanning from $650-4,000 \mathrm{~cm}^{-1}$.

The Raman spectra of the nanocarbon materials were obtained using a Raman spectroscope (Senterra R200-L) in the range of $50-3,500 \mathrm{~cm}^{-1}$ with a laser source wavelength of $532 \mathrm{~nm}$.

The XRD spectra were obtained using a D-MAX 2200/PC x-ray diffractometer (Japan Rigaku Corp.) operating under the condition of $2 \theta=5^{\circ}-60^{\circ}$ at a speed of $4^{\circ} \cdot \mathrm{min}^{-1}$ with $\mathrm{Cu} \mathrm{K} \alpha$ radiation $(\lambda=0.154 \mathrm{~nm})$.

Thermostability was achieved using Q600 (TA Instruments, USA) under an $\mathrm{N}_{2}$ atmosphere at $100 \mathrm{~mL} / \mathrm{min}$ with $10{ }^{\circ} \mathrm{C} / \mathrm{min}$ temperature programmed from room temperature to $800{ }^{\circ} \mathrm{C}$.

The microtopography of the NCMs were obtained by a Phenom Pro scanning electron microscope (Phenom World, Holland).

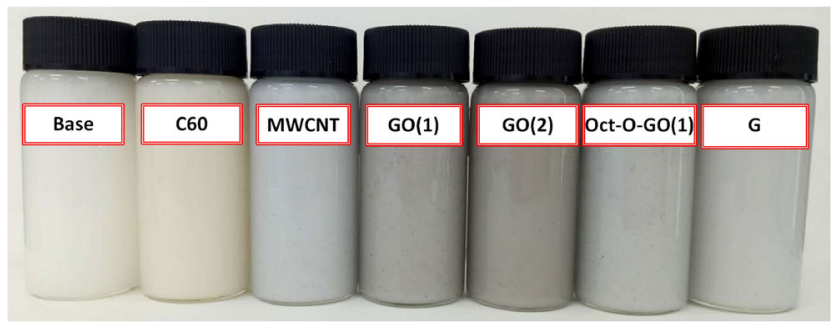

Fig. 1 Images of $\mathrm{O} / \mathrm{W}$ emulsions with NCMs.
The water static contact angle was tested using an optical contact angle measuring instrument (DSA30, Kruss, Germany) by injecting one drop of $30 \mu \mathrm{L}$ of $\mathrm{H}_{2} \mathrm{O}$ on the surface of the tablet made of NCMs, which was made from a $\sim 1 \mathrm{~g}$ sample under $25 \mathrm{MPa}$ for $6 \mathrm{~min}$ using a desktop electric powder tablet presser (Tianjin Sichuang Technology Development Co. Ltd., China ).

The viscosity test was carried out using a rheometer AR-G2 (TA, USA) under various shear speeds that ranged from $0.01-30 \mathrm{rad} / \mathrm{s}$ for $240 \mathrm{~s}$ at $25^{\circ} \mathrm{C}$. The droplet size of the emulsions was monitored using an optical microscope with measuring software (CK-330C, Caikon, China), and the droplet size was taken as the average value of ten measurement sets.

\subsection{Tribological test}

The tribological performances of the lubricants with different NCMs were evaluated using a high-frequency reciprocating friction and wear tester (Rtec, USA). The upper ball ( $5 \mathrm{~mm}$ in diameter, 304 stainless steel) rubbed against the stationary lower steel plate $(50 \mathrm{~mm} \times$ $25 \mathrm{~mm} \times 2 \mathrm{~mm}, 304$ stainless steel, roughness $\mathrm{Ra}=0.8 \pm$ $0.3 \mathrm{um})$. Before the test, all the balls and plates were washed twice. They were first ultrasonicated with a mixture of petroleum and ethanol ( $\mathrm{v}: \mathrm{v}=1: 9)$ for $5 \mathrm{~min}$, then ultrasonic washed with petroleum for $3 \mathrm{~min}$. Thereafter, $5 \mathrm{~mL}$ of lubricant was applied to the ballplate contact area for the tests, which were conducted with a stroke of $10 \mathrm{~mm}$ under a frequency of $0.5 \mathrm{~Hz}$ with reciprocating sliding for $3 \mathrm{~min}$. The applied nominal pressure was approximately $1.73 \mathrm{GPa}$ with a normal load of $50 \mathrm{~N}$, and $2.18 \mathrm{GPa}$ for $100 \mathrm{~N}$. The sliding distance of each test was $1,800 \mathrm{~mm}$. All the samples were tested three times under each experimental condition, and the COF was recorded automatically by the tribotester.

The load-carrying capacity (maximum non-seized load $P_{\mathbf{B}}$ and the weld load $P_{\mathrm{D}}$ of all the NCM emulsions) was tested using a four-ball test machine (MS-10A, Xiamen Tenkey Automation Co., Ltd., China). The test standard used was GB/T 3142-82, and the ball used in the four-ball tests was a 304 stainless steel ball with a diameter of $12.7 \mathrm{~mm}$.

\subsection{Worn surface analysis}

After the tribological tests, the tested balls and plates 
were ultrasonic washed with petroleum for $1 \mathrm{~min}$ and $4 \mathrm{~min}$. The wear volumes of the worn balls and plates were measured using a non-contact 3D surface interferometer (Bruker, Contour GT, USA) after the tribological test. The worn surface morphologies of the plates were also examined using a 3D color confocal laser scanning microscope (Keyence, VK-9700K, Japan) with a magnification of 10×. The micro-Raman spectra of the worn scars on the balls after the four-ball tests under a load of $660 \mathrm{~N}$ were obtained using a DXRTM xi Raman imaging spectroscope (Thermo Fisher Scientific, USA) in the range of $50-3,500 \mathrm{~cm}^{-1}$, with a laser source wavelength of $532 \mathrm{~nm}$. The SEM images were captured and the EDS analysis of the worn balls after the tribological tests under $100 \mathrm{~N}$ was performed using an EVO18 (ZEISS, Germany). The chemical composition on the wear tracks was determined using XPS with $\mathrm{Al} \mathrm{K} \alpha$ radiation as the exciting source. The binding energies of the target elements were determined at the pass energy of $29.35 \mathrm{eV}$ with a resolution of approximately $70.3 \mathrm{eV}$, using the binding energy of contaminated carbon (C 1s: $284.8 \mathrm{eV}$ ).

\section{Results and discussion}

\subsection{Characterization of GO and Oct-O-GO}

The infrared (IR) spectrum as one of the four spectrums of organic structure analysis can be used to effectively identify structure and functional groups in compounds. The FTIR spectra of GO(1), GO(2), and Oct-O-GO(1) are presented in Fig. 2(a). From the $1,053 \mathrm{~cm}^{-1}$ (C-O vibration), 1,225 cm $\mathrm{cm}^{-1}$ (C-O-C), 1,384 $\mathrm{cm}^{-1}$ (C-O bonds of carboxyl), $1,621 \mathrm{~cm}^{-1}$ (skeletal vibration of $\mathrm{C}=\mathrm{C}$ bonds in GO) [42], 1,736 $\mathrm{cm}^{-1}(\mathrm{C}=\mathrm{O}$ stretching of carboxylic acid), and $3,400 \mathrm{~cm}^{-1}$ (O-H vibration) in the FTIR spectra, it is confirmed that the GO prepared in this work contained carboxyl groups, carbonyl groups, hydroxyl groups, and epoxy groups. Moreover, the oxidation degree of $\mathrm{GO}(2)$ was higher than that of $\mathrm{GO}(1)$ with respect to the intensity of transmission (C-O-C, C-O and O-H vibration). The FTIR spectrum of Oct-O-GO(1) revealed the characteristic bands of the alkyl groups corresponding to the modification with n-Octanol. In particular, the peaks at $2,853 \mathrm{~cm}^{-1}$ and $2,924 \mathrm{~cm}^{-1}$ are attributed to the symmetric and asymmetric stretching vibration of the alkyl groups, respectively [43]. Moreover, there were several characteristic bands of epoxy groups and no carboxyl groups in the FTIR spectrum of Oct-O-GO(1), which indicates that the carboxyl groups in Oct-O-GO(1) reacted with n-Octanol.

By unscrambling the XRD spectra, the composition and internal information such as atomic or molecular structure of the materials can be speculated; thus, it is also an important analysis method for carbon materials. Figure 2(b) displays the XRD spectra of $\mathrm{GO}(1), \mathrm{GO}(2)$, and Oct-O-GO(1). Both GO(1) and GO(2) exhibited the characteristic diffraction peak of graphene oxide $\left(2 \theta \sim 10^{\circ}\right)$, whereas that of Oct-O-GO(1) shifted to $24.031^{\circ}$ (Fig. 2(b)). According to the Bragg Law [31] $(n \lambda=2 d \sin \theta)$ and Scherrer equation [44] $(D=k \lambda / \beta \cos \theta)$ (where $n$ is the diffraction series, $\lambda$ is the $\mathrm{X}$-ray wavelength, $d$ is the interlayer spacing, $D$ is the mean diameter of the crystalline grain, $k$ is the shape factor, and $\beta$ is the fullwidth at half maximum), an approximate calculation of the interlayer distance $[36,45]$ in different materials was performed, as shown in Table 2. Compared with the characteristic peak of graphite at approximately $26.58^{\circ}$ [46], the diffraction peak of GO shifted to the left. The disappearance of the characteristic peak of graphite indicates that $\mathrm{GO}(1)$ and $\mathrm{GO}(2)$ were successfully prepared. From Table 2, it can be seen that the interlayer distance of $\mathrm{GO}(2)$ was
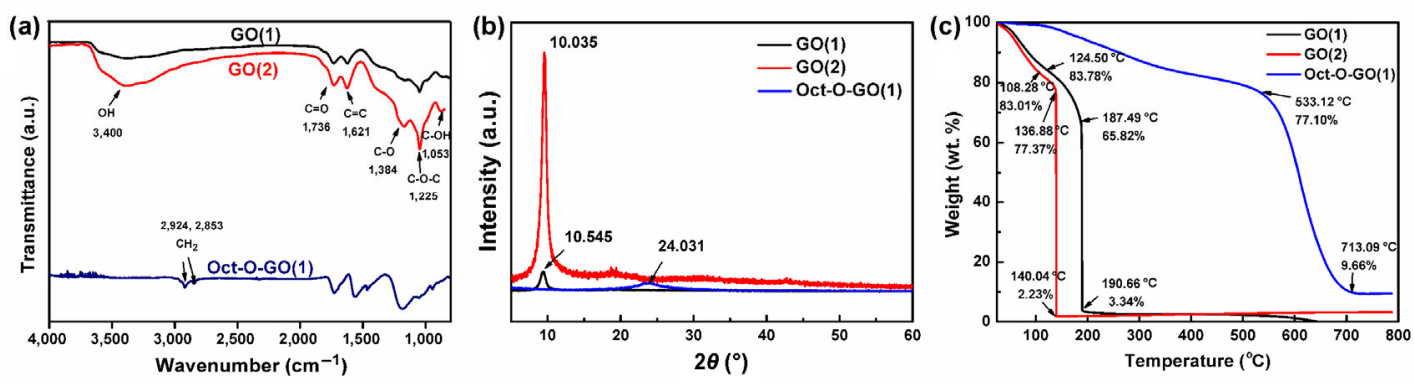

Fig. 2 FTIR, XRD, and TG analysis of $\mathrm{GO}(1), \mathrm{GO}(2)$, and Oct-O-GO(1). 
larger than that of $\mathrm{GO}(1)$, which further confirmed that the oxidation degree of $\mathrm{GO}(2)$ was higher than that of $\mathrm{GO}(1)$. In comparison with $\mathrm{GO}(1)$, the $2 \theta$ peak of Oct-O-GO(1) was wider and weaker, and the interlayer distance was smaller. This may be due to the decrease in the number of oxygen-containing groups after its modification with octanol. The decrease in the number of oxygen-containing groups reduced the hydrogen-bond interaction between layers; thus, the interlayer spacing decreased [36].

The results of the thermostability of $\mathrm{GO}(1), \mathrm{GO}(2)$, and Oct-O-GO(1) are presented in Fig. 2(c) and Table 3. For $\mathrm{GO}(1)$ and $\mathrm{GO}(2)$, two clear gravity gradients were present, namely, (1) the first decrease in mass due to a small number of free water or combined water in molecules from $50{ }^{\circ} \mathrm{C}$ to $130{ }^{\circ} \mathrm{C}$ [47], and (2) the second gravity gradient between $130^{\circ} \mathrm{C}$ and $300{ }^{\circ} \mathrm{C}$, which was mainly due to the decomposition of oxygencontaining functional groups on the surface and edge of the graphite oxide. Moreover, the process may generate $\mathrm{CO}, \mathrm{CO}_{2}$, and $\mathrm{H}_{2} \mathrm{O}$ [48]. From the TGA curve, it can be seen that $\mathrm{GO}(2)$ was easier to decompose than $\mathrm{GO}(1)$, which may contribute to the higher content of oxygen groups. However, the remaining mass of $\mathrm{GO}(1)$ and $\mathrm{GO}(2)$ rapidly approached to zero after decomposition, which was probably due to the energy released by degradation. Furthermore, this had a temporary effect on the balance of the measuring

Table 2 Theoretical calculation of the interlayer distance.

\begin{tabular}{ccc}
\hline Samples & $2 \theta\left(^{\circ}\right)$ & Interlayer distance $(\mathrm{nm})$ \\
\hline $\mathrm{G}$ & 26.580 & $0.340^{17}$ \\
$\mathrm{GO}(1)$ & 10.545 & 0.747 \\
$\mathrm{GO}(2)$ & 10.035 & 0.785 \\
Oct-O-GO(1) & 24.031 & 0.326 \\
\hline
\end{tabular}

Table 3 Thermo gravimetric analysis (TGA).

\begin{tabular}{ccc}
\hline Sample & Temperature $\left({ }^{\circ} \mathrm{C}\right)$ & Mass remaining $(\%)$ \\
\hline $\mathrm{GO}(1)$ & 124.50 & 83.78 \\
& 187.49 & 65.82 \\
& 190.66 & 3.34 \\
$\mathrm{GO}(2)$ & 108.28 & 83.01 \\
& 136.88 & 77.37 \\
& 140.04 & 2.23 \\
Oct-O-GO(1) & 533.12 & 77.10 \\
& 713.09 & 9.66 \\
\hline
\end{tabular}

instrument, thus decreasing its sensitivity [49]. Form the results, it can be seen that the thermostability of Oct-O-GO(1) is better than that of GO, which can be attributed to the n-Octanol modified carboxyl. It is common knowledge that the thermostability of ester is better than that of carboxylic acid. After $500{ }^{\circ} \mathrm{C}$, most of the oxygen-containing functional groups on the layers were removed; however, there was still a decrease in mass, which was possibly due to the destruction of the carbon skeleton [50].

Raman spectroscopy is a useful technique for the characterization of $\mathrm{sp}^{2}$ and $\mathrm{sp}^{3}$ hybridized carbon atoms, including those in graphite, fullerenes, carbon nanotubes, and graphene [51]. The G band corresponds to the in-plane vibration of $\mathrm{sp}^{2}$-bonded carbon in a hexagonal lattice, and the D band associated with various types of disorder in the $\mathrm{sp}^{2}$ lattice. Figure 3 presents the Raman spectra of the nanocarbon materials used in this study. For C60 (Fig. 3(a)), the highest peaks were located at $1,457.17 \mathrm{~cm}^{-1}$ and $491.76 \mathrm{~cm}^{-1}$, and consisted of the Ag symmetry assignment for this mode [52, 53]. The observed Raman characteristics of MWCNT (Fig. 3(b)) were very similar to those of commercial MWCNT, which was analyzed by Santangelo et al. [54]. In particular, the $D$ and $G$ bands were at $1,337.60 \mathrm{~cm}^{-1}$ and $1,573.73 \mathrm{~cm}^{-1}$, respectively. From the Raman spectrum of graphite, it can be inferred that the graphite used contained defects and disorder, as indicated by the $\mathrm{D}$ band at $1,354.82 \mathrm{~cm}^{-1}$ (Fig. 3(c)) [55].

Furthermore, GO(1), GO(2), and Oct-O-GO(1) exhibited $D$ and $G$ bands at approximately $1,340 \mathrm{~cm}^{-1}$ and $1,580 \mathrm{~cm}^{-1}$, respectively (Fig. 3(d)) [56]. Origin 8.0 was used to fit the points in the Raman spectra after peak processing, for the calculation of the area ratio of the $G$ and $D$ peaks $\left(I_{D} / I_{G}\right.$ : D and $G$ peak relative strengths). It can be used to estimate the content between the $\mathrm{sp}^{3}$ and $\mathrm{sp}^{2}$ hybridization of carbon atoms, which can distinguish the disorder of the graphite crystal structure. In the oxidation process, the $\mathrm{sp}^{2}$ hybridization of the graphite carbon atoms in the network structure converts to $\mathrm{sp}^{3}$ hybridization for the destruction of the carbon network. The $I_{\mathrm{D}} / I_{\mathrm{G}}$ ratio of $\mathrm{GO}(1), \mathrm{GO}(2)$, and Oct-O-GO(1) was 1.793, 2.409 and 2.481 , respectively. This meant a decrease in the size of in-plane $\mathrm{sp}^{2}$ domains, as well as an increase in the number density of grain boundaries that contained 

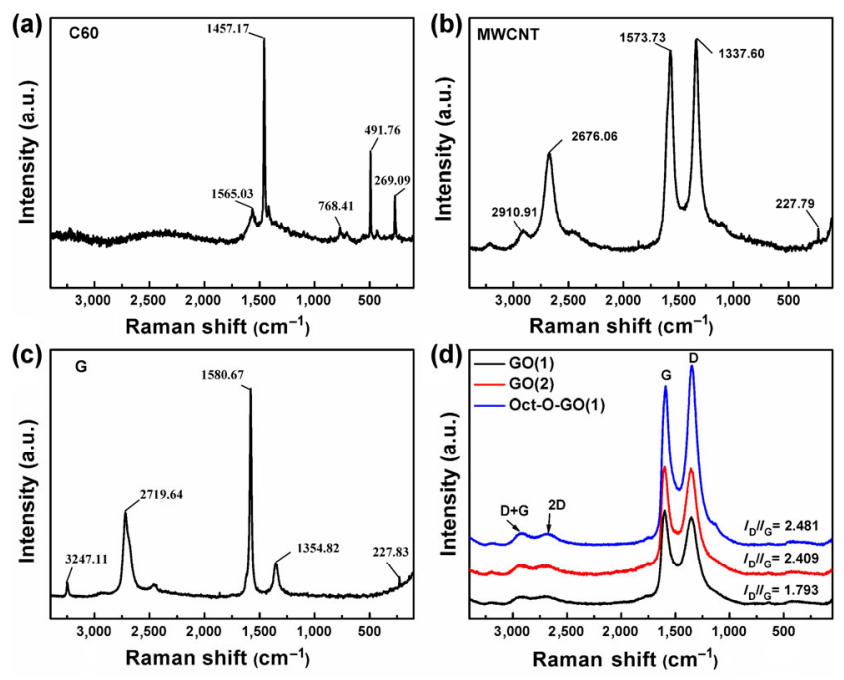

Fig. 3 Raman spectra of (a) C60; (b) MWCNT; (c) G; (d) $\mathrm{GO}(1), \mathrm{GO}(2)$ and Oct-O-GO(1).

various defects in $\mathrm{GO}(2)$ and Oct-O-GO(1). This confirmed that under the $\mathrm{H}_{2} \mathrm{SO}_{4}$ and $\mathrm{H}_{3} \mathrm{PO}_{4}$ mixed acid condition, $\mathrm{GO}(2)$ exhibited a more disordered crystal structure, which implies that the oxidation degree of $\mathrm{GO}(2)$ was higher [57]. In particular, Oct-O-GO(1) exhibited an increased $\mathrm{D} / \mathrm{G}$ intensity ratio in comparison with GO, thus indicating a decrease in the average size of the $\mathrm{sp}^{2}$ domains upon reaction with $-\mathrm{COOH}$. The $2 \mathrm{D}$ band at $2,690 \mathrm{~cm}^{-1}$ is attributed to transverse optical phonon modes near the high symmetry point of the Brillouin zone ( $K$ point), which arises due to a two-phonon double-resonance process. This peak was poorly developed, which indicates disordered graphene layers and stacking faults. The $D+G$ peak is a combination mode of the D and G bands, and it appears in the graphite lattice with a high defect density [58].

The microtopography of the NCMs are presented in Fig. 4. The particle size distribution of C60 was not uniform, MWCNT appeared fluffy, and the graphite was layered. Multi-layer fold sheets could be clearly observed in $\mathrm{GO}(1), \mathrm{GO}(2)$, and Oct-O-GO(1), which was the characteristic appearance of the graphite oxide prepared by Hummers' method [59]. This is because the oxidation group mostly exists on the surface and edges of the pieces, which can give rise to the thin film structure with curls and folds due to van der Waals forces, i.e., hydrogen-bond interactions and $\Pi-\Pi$ stacks [60]. The wrinkles of Oct-O-GO(1) were less than that of $\mathrm{GO}(1)$ and $\mathrm{GO}(2)$, as it had been modified with n-octanol, which decreased the hydrogen-bond interaction to a certain extent.

\subsection{Surface wettability test}

The water static contact angle reveals the surface wetting characteristics. The wettability differs for different microstructures and functional groups. From Fig. 5, it can be seen that both $\mathrm{GO}(1)$ and $\mathrm{GO}(2)$ had
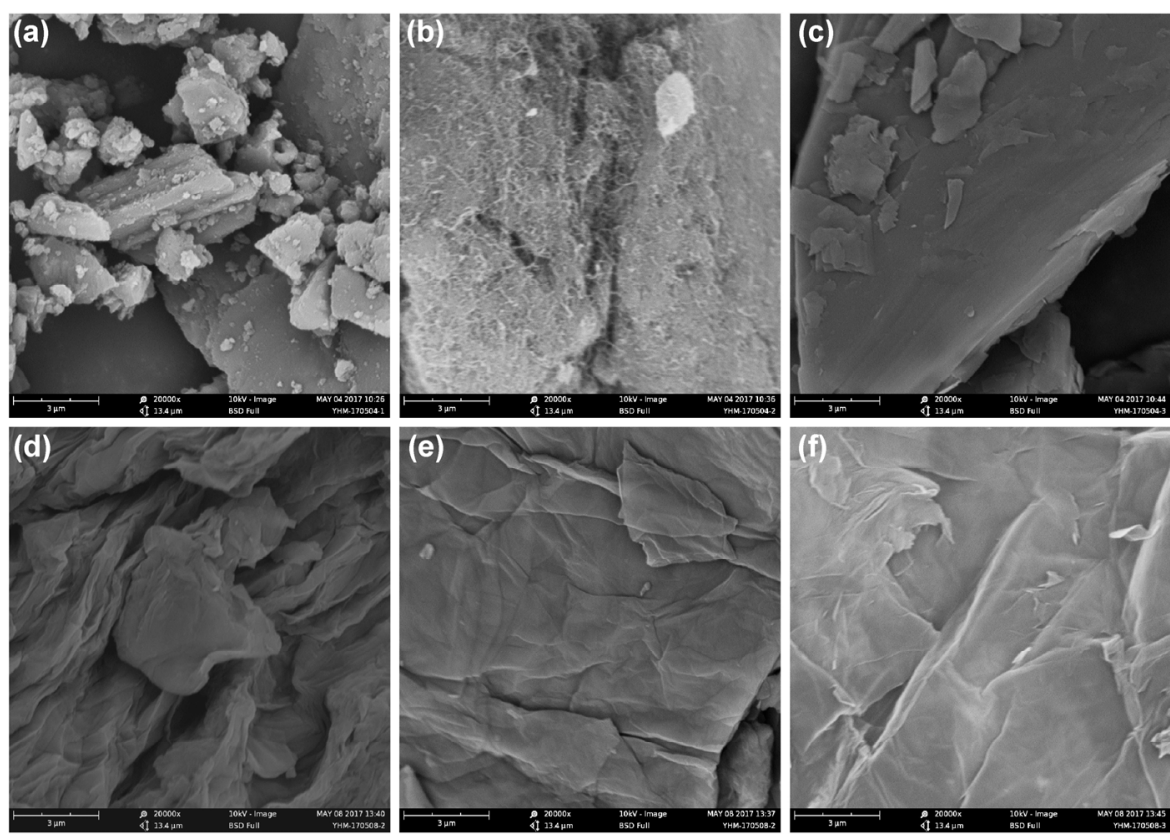

Fig. 4 SEM images of (a) C60; (b) MWCNT; (c) Graphite; (d) GO(1); (e) GO(2); (f) Oct-O-GO(1). 


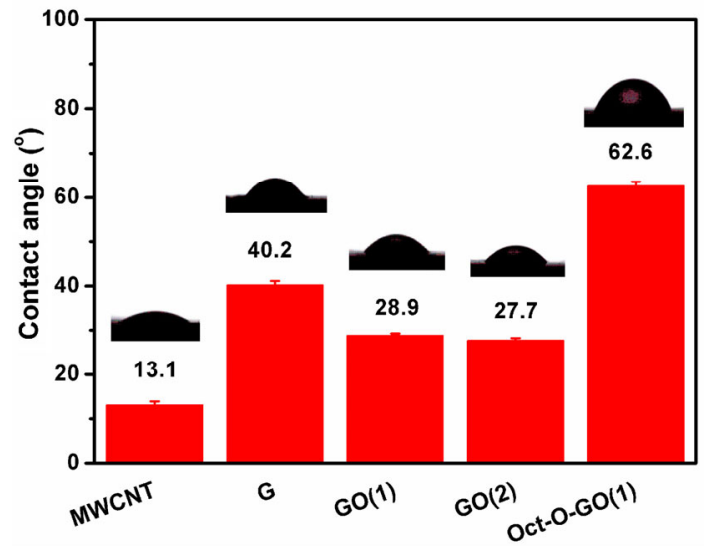

Fig. 5 The schematic overview of surface wettability test and the static contact angles of NCMs.

a better wettability than the pristine graphite, due to the oxygen-containing functional groups. Moreover, $\mathrm{GO}(2)$ was more hydrophilic in comparison with $\mathrm{GO}(1)$, which further confirmed that a larger amount of oxygen-containing functional groups were present on $\mathrm{GO}(2)$ than on $\mathrm{GO}(1)$. With respect to organic modification, Oct-O-GO(1) revealed a higher static contact angle at approximately $62.6^{\circ}$, thus resulting in decreased hydrophilicity.

\subsection{Characterization of the emulsions}

Viscometry is one of the most widely used investigation methods for colloidal solutions, which can effectively reflect the stability and rheological properties of emulsions [61]. Figure 6 presents the viscosity curves and size changes of the emulsions. From the viscosity curves of the emulsions in Fig. 6(a), it can be inferred that all the emulsions were shear-thinning liquids, which belonged to non-Newtonian fluids. Moreover, all the emulsions exhibited similar viscosities. From Fig. 6(b), it can be seen that there was a slight general decrease in the size of the emulsion droplets in all the samples over time, suggesting that all the emulsions had good stabilities.

\subsection{The tribological performance}

\subsubsection{The load-carrying capacity}

The results of the tribological tests are presented in Fig. 7. The emulsions with NCMs exhibited better load-carrying capacities with respect to the $P_{\mathrm{B}}$ values (Fig. 7(d)), when compared with the base emulsion. Moreover, the Oct-O-GO(1) emulsion yielded a prominent $P_{\mathrm{D}}$ value, whereas those of other NCM emulsions were similar to that of the base emulsion.

\subsubsection{The friction-reducing property}

For the same sample tested under the same frequency, the average COF under $100 \mathrm{~N}$ was smaller than that under $50 \mathrm{~N}$ during the relatively stable period (70-180 s) (Fig. 7(c)). This was because within a certain load range, with an increase in pressure, the emulsion droplet was more easily broken, and the released oil phase and emulsifiers could quickly form lubrication films to reduce the COF. Emulsions with different NCMs demonstrated different friction-reducing performances, and the COFs when the load was $50 \mathrm{~N}$ can be ranked as follows: Oct-O-GO(1) emulsion $<\mathrm{GO}(2)$ emulsion $<$ MWCNT emulsion $<$ C60 emulsion $<$ base emulsion < GO(1) emulsion < G emulsion; whereas when the load was $100 \mathrm{~N}$, it can be ranked as Oct-O$\mathrm{GO}(1)$ emulsion < $\mathrm{GO}(1)$ emulsion $<\mathrm{C} 60$ emulsion $<$ $\mathrm{GO}(2)$ emulsion $<$ MWCNT emulsion $<$ base emulsion $<$ $\mathrm{G}$ emulsion. The emulsion with Oct-O-GO(1) demonstrated a better friction reducing performance than that with the other NCMs under $50 \mathrm{~N}$ and $100 \mathrm{~N}$. This
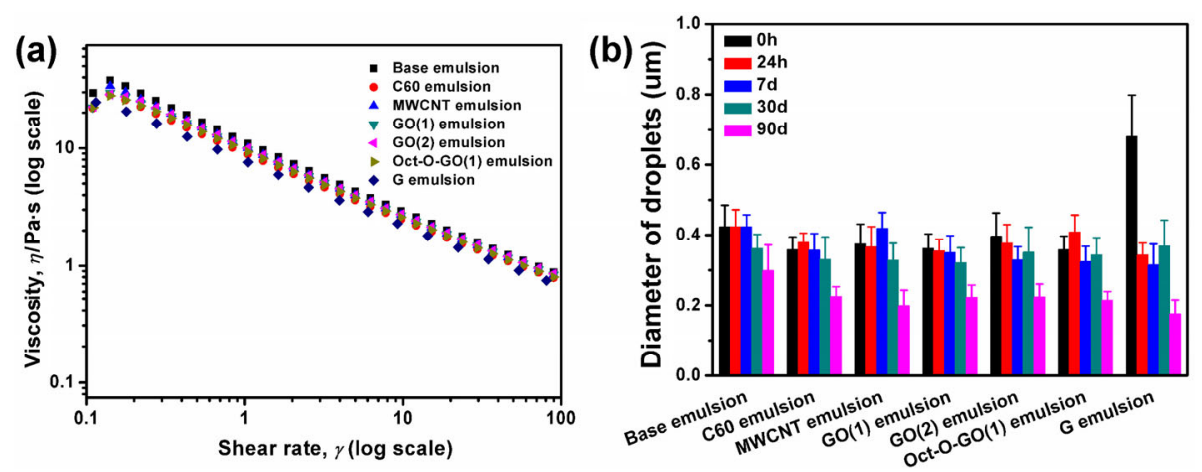

Fig. 6 (a) The viscosity curve of emulsions and (b) the size change of emulsion droplets over time. 

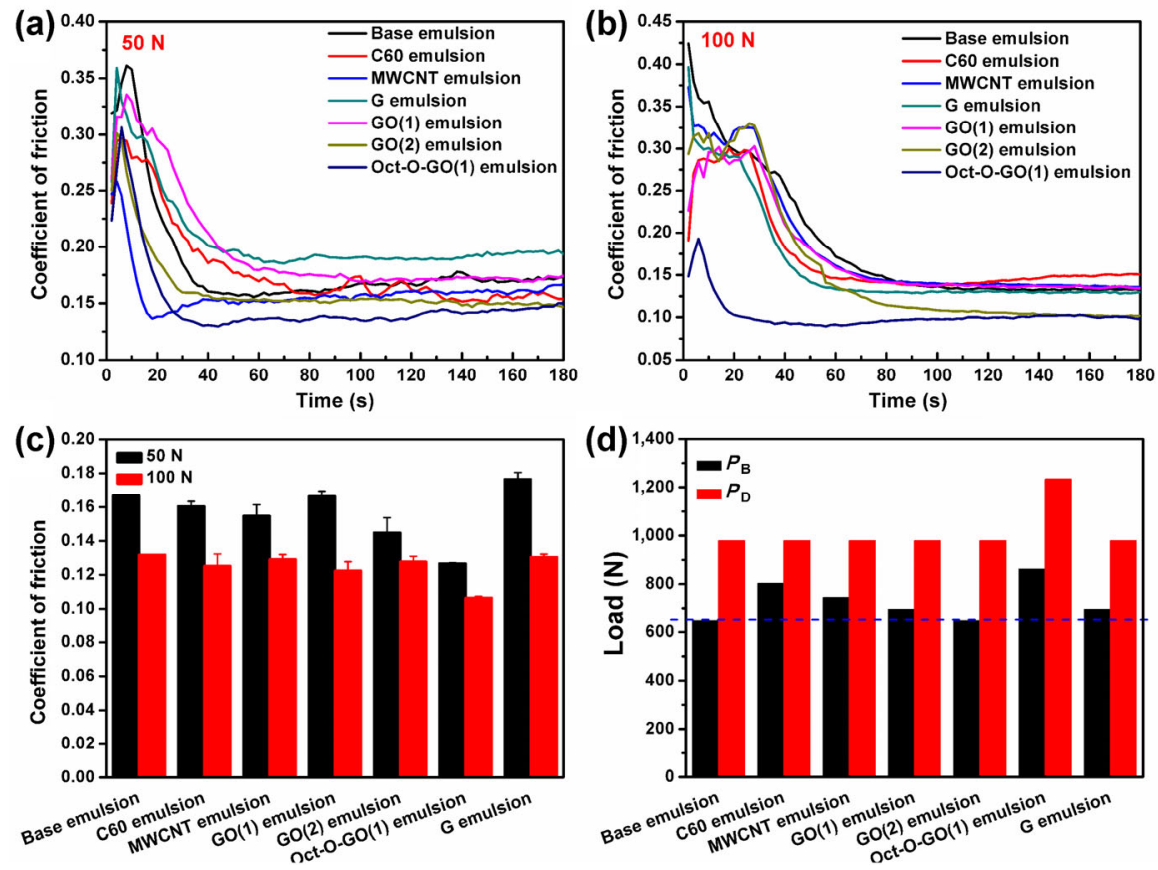

Fig. 7 Friction profile of emulsions during the whole test period (0-180 s) under (a) $50 \mathrm{~N} \&$ (b) $100 \mathrm{~N}$; (c) the average COF of emulsions during relative stable period (70-180 s) under $50 \mathrm{~N}$ and $100 \mathrm{~N}$; (d) the $P_{\mathrm{B}}$ and $P_{\mathrm{D}}$ values of NCMs emulsions.

may be because of its increased solubility in PAO8, due to the alkyl chains of graphene oxide. Therefore, during sliding, when the oil droplets of the emulsions were broken, the hydrophilic region of Oct-O-GO(1) interacted with the metal surface, whereas the alkyl chain of Oct-O-GO(1) stretched out in the PAO8 base oil to form a compact and well ordered thick interfacial film. This resulted in a better friction reducing performance. However, the friction reducing properties of other NCMs were similar, which was probably because they held the same carbon skeleton structure. When compared with the base emulsion, almost all the emulsions with NCMs played the role of frictionreducing, with the exception of that with graphite. This may be because it is difficult for graphite to be dispersed in oil or water. Other NCMs were more easily dispersed in the aqueous or oil phase, and emulsions with other NCMs as lubricants demonstrated better friction reducing performances than the base emulsion. In terms of the friction profiles, the Oct-O-GO(1) emulsion had the lowest COF and shortest running-in period. This was possibly because the alkyl chains on graphene oxide can arrange rapidly and directionally to form a protective film on the friction pairs, especially under a higher load $(100 \mathrm{~N})$.

\subsubsection{The anti-wear property}

The anti-wear performances of the NCM emulsions were studied using 3D surface interferometer analysis and confocal surface analysis, and the results are presented in Table 4, in which the colored images are from the interferometer analysis, and the grey images are from the confocal surface analysis. From the 3D surface interferometer analysis, the wear volume could be obtained, and the corresponding wear rate could be calculated. The wear rates of the worn balls and plates after the tribological tests under $100 \mathrm{~N}$ are presented in Fig. 8. For all the emulsions, the scratches under $100 \mathrm{~N}$ were more severe than those under $50 \mathrm{~N}$ (see Table 4). This suggested that at the same condition, a larger load resulted in more severe wear.

The 3D contour images revealed that the Oct-O-GO(1) emulsion exhibited a better anti-wear performance when compared with the other emulsions, regardless of whether the load was $50 \mathrm{~N}$ or $100 \mathrm{~N}$, and this advantage was more prominent under the high load condition. The surface of the rubbing pair lubricated with the Oct-O-GO(1) emulsion was smooth, and no significant furrows were observed, whereas that lubricated with other emulsions was rough, and different-sized furrows were present. The wear rates 
Table 4 3D contour and confocal (50×) pictures of scratches on balls and plates after tribological tests under $50 \mathrm{~N}$ and $100 \mathrm{~N}$.

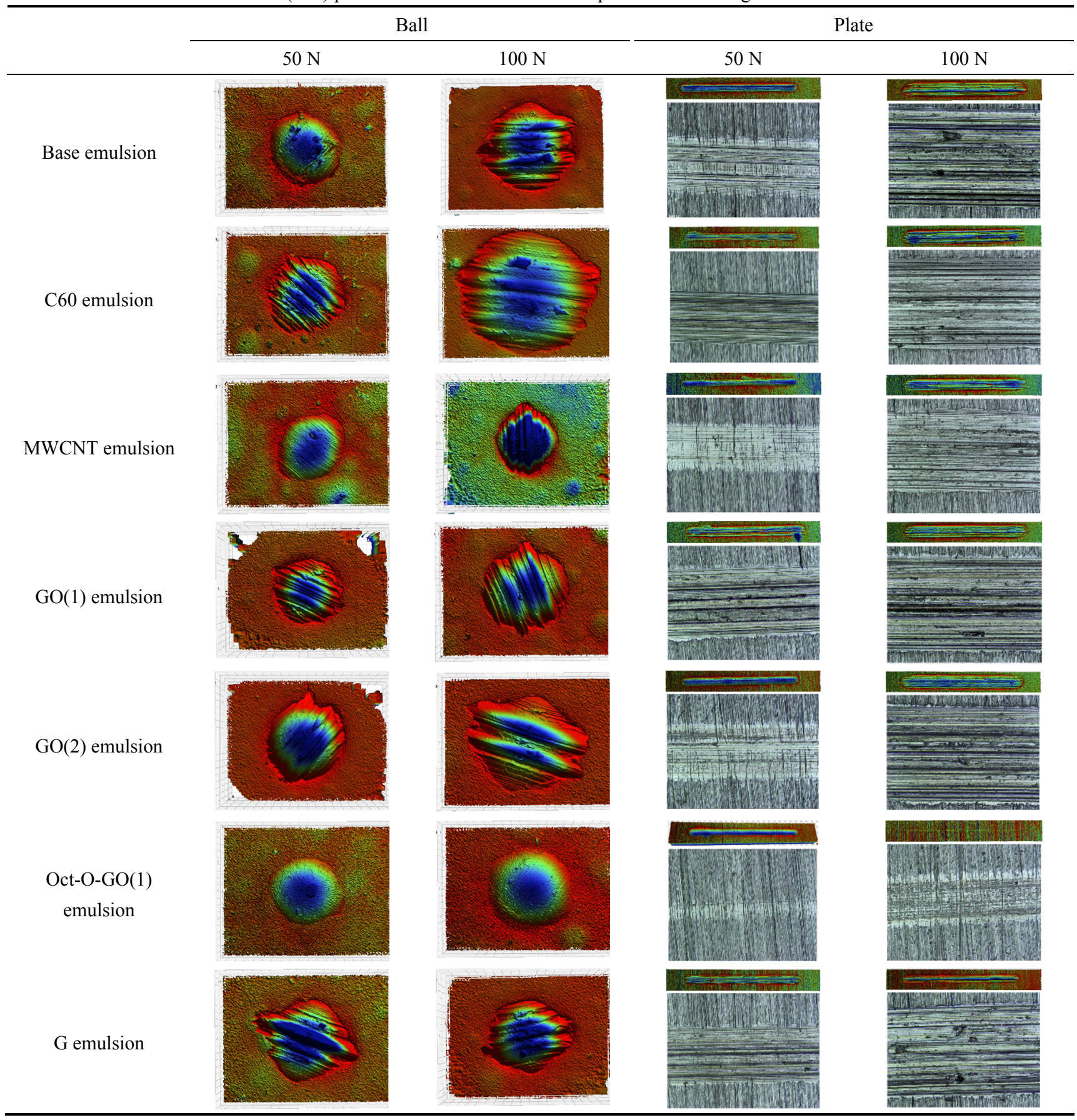

of worn plate surfaces after the tribological tests under $100 \mathrm{~N}$, as shown in Fig. 8, can be ranked as follows: Oct-O-GO(1) emulsion < G emulsion < MWCNT emulsion $<\mathrm{GO}(1)$ emulsion $<\mathrm{C} 60$ emulsion $<\mathrm{GO}(2)$ emulsion $<$ base emulsion. The results further indicated that the Oct-O-GO(1) emulsion exhibited the best anti-wear property.

Compared with white-light interference, laser confocal scanning offers a higher resolution, and can achieve a narrow-range evaluation to obtain true color images. When the load was $100 \mathrm{~N}$, the scratches on the plates lubricated with the Oct-O-GO(1) emulsion and base emulsion were the shallowest and the deepest, respectively, which is consistent with the results of the 3D interferometer analysis. In addition, there was a certain degree of abrasive wear and adhesive wear 


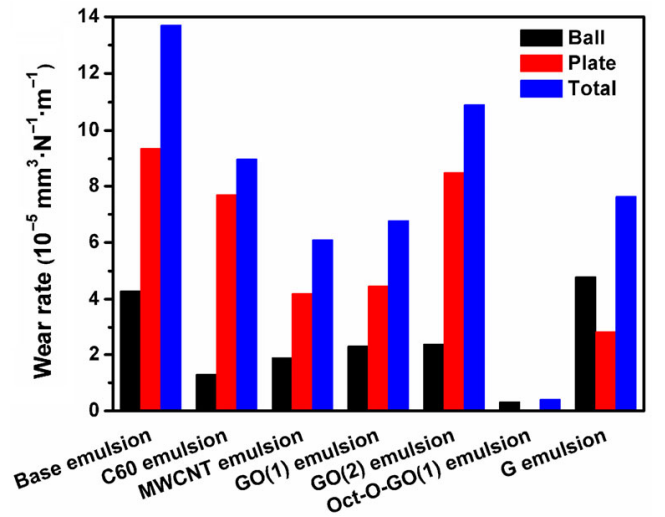

Fig. 8 Wear rate of balls, plates and total wear rate of ball \& plate after the tribological tests under $100 \mathrm{~N}$ with different NCM.

for all the emulsions, with the exception of that with Oct-O-GO(1). This was probably because the emulsion with Oct-O-GO(1) formed a uniform and stable lubricating film due to the combined effect of the alkyl chains and oxygen-containing functional groups on the GO skeleton.

\subsection{The lubrication mechanism}

To determine the lubrication mechanism of the NCM emulsions, surface analyses including SEM-EDS, Raman spectroscopy, and XPS were conducted.

\subsubsection{SEM-EDS analysis}

To better observe the surface topography, SEM was conducted, and several black fractions on the worn surfaces (Fig. 9) were detected. Consequently, EDS analysis was employed to investigate the composition of the fractions on the worn surfaces. According to Table 5, C, O, Fe, Cr, Ni, and several other elements were detected in the magnifying region of the worn scars. The fresh surface of the friction pairs mainly contained $\mathrm{Fe}, \mathrm{Cr}, \mathrm{Ni}$, and small amounts of $\mathrm{C}$ and $\mathrm{Si}$, whereas the lubricants (NCM emulsions) contained $\mathrm{C}$ and $\mathrm{O}$. Compared with the EDS data of the worn surface lubricated by the base emulsion, it can be inferred that the presence of $C$ was mainly due to the residual NCM materials, whereas $\mathrm{O}$ was derived from the oxygen-containing ingredients. From the results of the EDS analysis, the order of the $\mathrm{C}$ and $\mathrm{O}$ contents from high to low was as follows: Oct-O-GO(1) emulsion $\sim \mathrm{C} 60$ emulsion $>$ MWCNT emulsion $>\mathrm{GO}(1)$ emulsion $\sim \mathrm{GO}(2)$ emulsion $\sim \mathrm{G}$ emulsion. In Fig. 8,

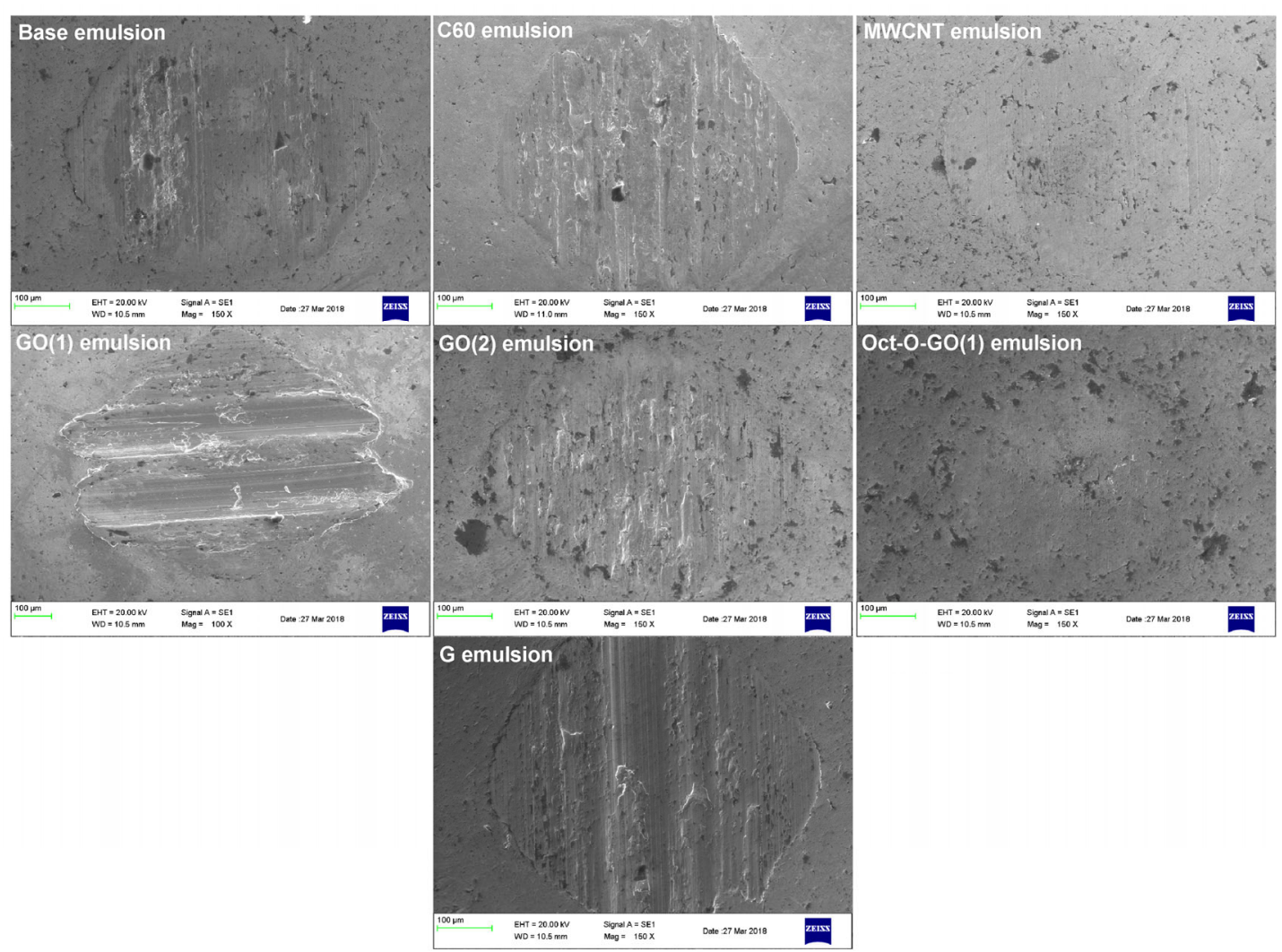

Fig. 9 SEM images $(150 \times)$ of scratches on balls after tribological tests under $100 \mathrm{~N}$. 
Table 5 EDS analysis of scratches on balls after tribological tests under $100 \mathrm{~N}$.

\begin{tabular}{cccccccc}
\hline $\begin{array}{c}\text { Element content } \\
(\%)\end{array}$ & $\begin{array}{c}\text { Base } \\
\text { emulsion }\end{array}$ & $\begin{array}{c}\text { C60 } \\
\text { emulsion }\end{array}$ & $\begin{array}{c}\text { MWCNT } \\
\text { emulsion }\end{array}$ & $\begin{array}{c}\text { GO(1) } \\
\text { emulsion }\end{array}$ & $\begin{array}{c}\text { GO(2) } \\
\text { emulsion }\end{array}$ & $\begin{array}{c}\text { Oct-O-GO(1) } \\
\text { emulsion }\end{array}$ & $\begin{array}{c}\text { G } \\
\text { emulsion }\end{array}$ \\
\hline $\mathrm{C}$ & - & 78.70 & 49.03 & 39.72 & 39.21 & 76.92 & 23.26 \\
$\mathrm{O}$ & 43.69 & 10.60 & 32.39 & 36.34 & 38.72 & 10.16 & 55.96 \\
$\mathrm{Na}$ & - & 0.71 & 0.92 & 0.87 & - & 0.62 & - \\
$\mathrm{Si}$ & - & - & 0.26 & 0.29 & 0.22 & 0.30 & 0.56 \\
$\mathrm{Cl}$ & - & 0.71 & 0.16 & 0.28 & 1.68 & 0.19 & 0.52 \\
$\mathrm{~K}$ & - & 0.13 & 0.15 & 0.22 & - & 0.12 & 0.30 \\
$\mathrm{Ca}$ & - & - & - & - & - & 0.20 & 0.21 \\
$\mathrm{Cr}$ & 13.09 & 2.16 & 4.33 & 5.12 & 2.89 & 2.51 & 5.60 \\
$\mathrm{Fe}$ & 39.34 & 6.68 & 11.63 & 15.67 & 15.76 & 8.01 & 12.20 \\
$\mathrm{Ni}$ & 3.88 & 0.64 & 1.13 & 1.49 & 1.53 & 0.96 & 1.38 \\
\hline
\end{tabular}

the rank of the wear rates of the worn ball surfaces was Oct-O-GO(1) emulsion < C60 emulsion < MWCNT emulsion $<\mathrm{GO}(1)$ emulsion $\sim \mathrm{GO}(2)$ emulsion $<\mathrm{G}$ emulsion. This implied that an increase in the $C$ and $\mathrm{O}$ contents in the film on the worn surface can result in an improved anti-wear property.

\subsubsection{Raman analysis}

Raman spectroscopy is commonly used to provide a structural fingerprint by which molecules can be identified. For Raman micro-spectroscopy (microRaman), sampling is non-destructive, and water, media, and buffers typically do not interfere with the analysis. Therefore, to better understand the lubricating mechanism of NCM emulsions, the Raman responses of the worn surfaces after four-ball tests were investigated. The micro-Raman results (Fig. 10) revealed six main peaks, which corresponded to alkyl chains $\left(840 \mathrm{~cm}^{-1}\right.$ and $\left.2,220 \mathrm{~cm}^{-1}\right)$, a carbon aggregation $\left(1,250 \mathrm{~cm}^{-1}\right)$, a D peak $\left(1,370 \mathrm{~cm}^{-1}\right)$, a $\mathrm{G}$ peak $\left(1,540 \mathrm{~cm}^{-1}\right)$, and a $2 \mathrm{D}$ peak $\left(2,760 \mathrm{~cm}^{-1}\right)$, respectively [62-64]. This demonstrated that all the NCM had residue on the worn surfaces when compared with the base. However, the micro-Raman spectra of the ball surfaces lubricated with $\mathrm{GO}(1), \mathrm{GO}(2), \mathrm{G}$, and MWCNT emulsions were similar, which only presented signals of the $D, G$, and 2D peak. Although they had similar Raman responses, the intensities of their response peaks varied. First, the total intensity of the $D$ and $G$ peaks for $G O(1)$ or $\mathrm{GO}(2)$ was higher than that of MWCNT, thus indicating differences in amounts of residue. Moreover, this was consistent with the SEM-EDS analysis. Second, for
$\mathrm{GO}(1)$ and $\mathrm{GO}(2)$, the intensity of the $\mathrm{D}$ peak was smaller than that of the G peak, whereas for MWCNT, the intensity of the D peak was a slightly higher than that of the $G$ peak. This indicates a higher $\mathrm{sp}^{3}$ hybridization of carbon atoms in the MWCNT residual film. From Section 3.4.3, it was confirmed that the anti-wear performance of MWCNT was superior to that of $\mathrm{GO}(1)$ and $\mathrm{GO}(2)$, thus indicating that the carbon residue contributed to the anti-wear performance. As for that lubricated with the C60 and Oct-O-GO(1) emulsions, signals were similar except alkyl chains for Oct-O-GO(1). The worn surfaces of the balls lubricated with the C60 and Oct-O-GO(1) emulsions exhibited a certain degree of amorphous carbon agglomeration, which may be why their loadcarrying capacities were more prominent than that of the other emulsions (Fig. 7(d)). This further indicated that the accumulation of carbon was beneficial to

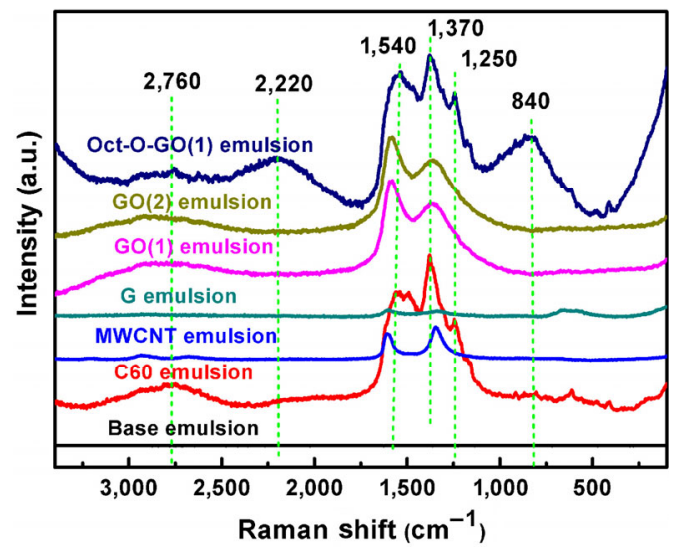

Fig. 10 Micro-Raman spectra of worn scars on balls after fourball tests under $660 \mathrm{~N}$. 
lubrication. The micro-Raman results of the Oct-O$\mathrm{GO}(1)$ emulsion presented two additional wide peaks $\left(840 \mathrm{~cm}^{-1}\right.$ and $\left.2,220 \mathrm{~cm}^{-1}\right)$, which can be attributed to alkyl chains. It indicated that the alkyl chains grafted onto GO sheets could be sheared during friction, and that the regions containing decomposed alkyl chains can be absorbed onto the freshly exposed metal surface, in addition to the carbon residue. Consequently, the Oct-O-GO(1) emulsion exhibited the best lubrication properties.

\subsubsection{XPS analysis}

X-ray photoelectron spectroscopy is mainly used to determine the binding energy of electrons and to identify the chemical properties and composition of sample surfaces. The main elements on the worn ball surfaces lubricated with NCMs emulsions after the tribological tests under $100 \mathrm{~N}$ are presented in Fig. 11, (a)

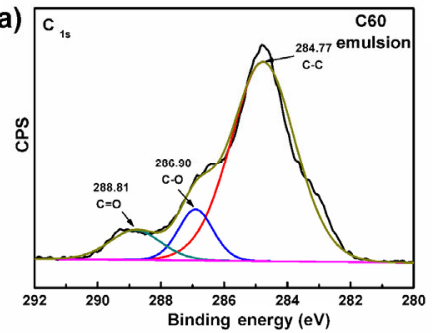

(d)

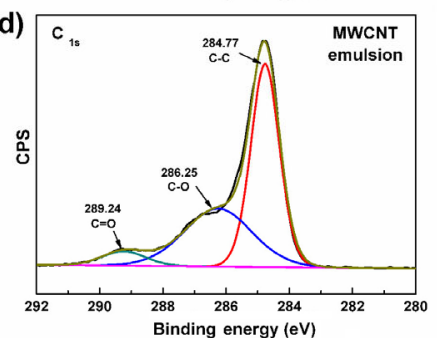

(g)
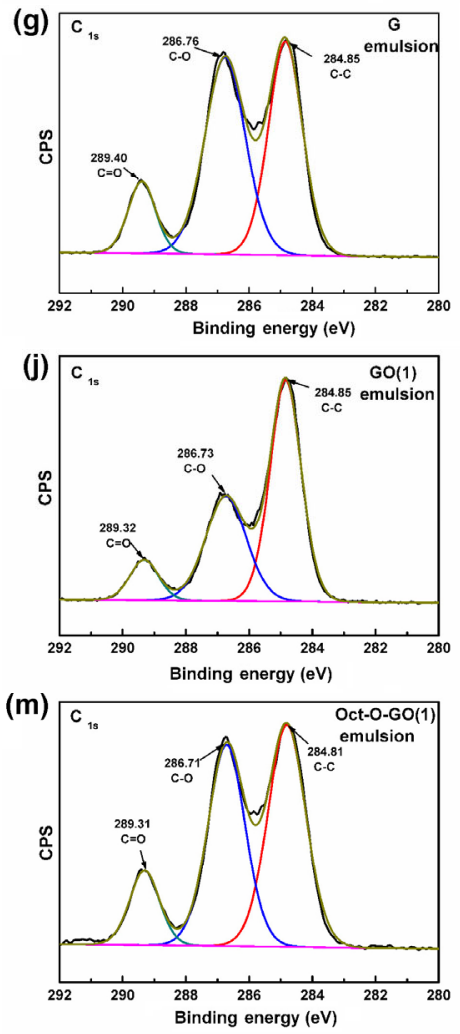

(b)

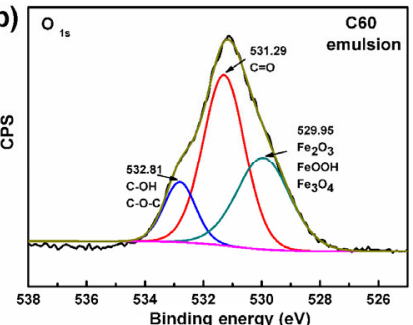

(e)

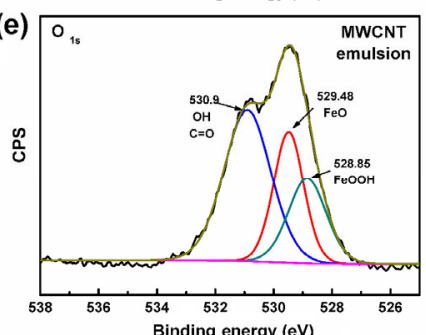

(h)

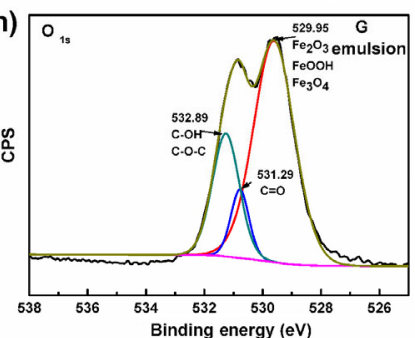

(k) 0
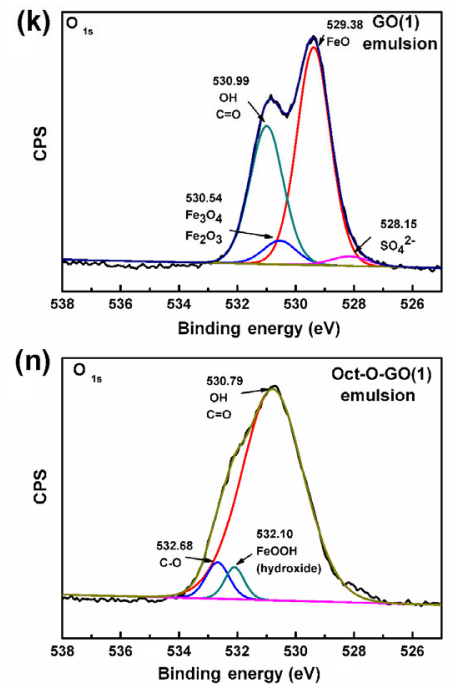
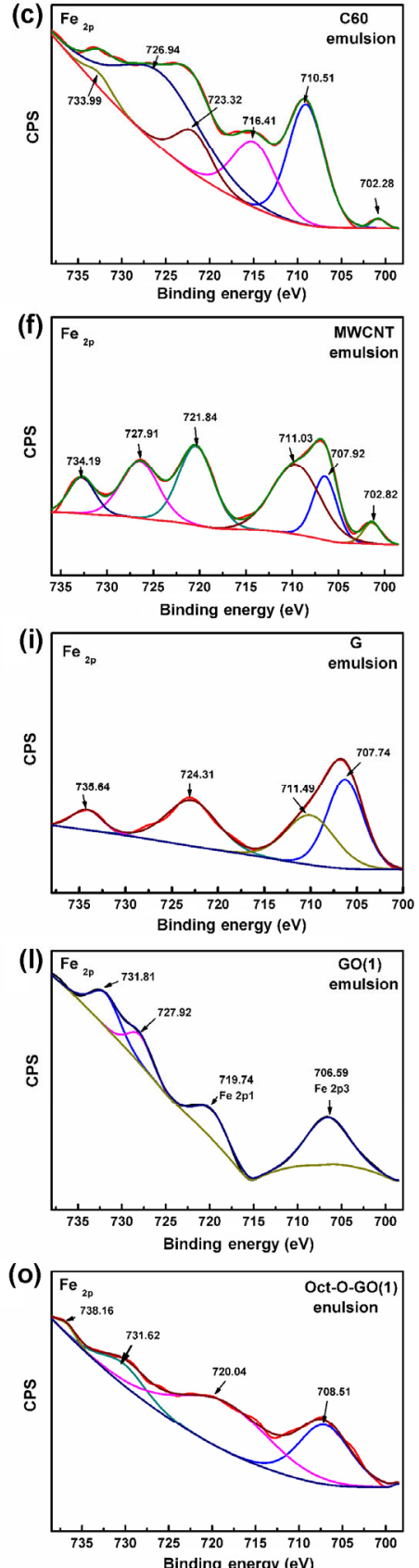

Fig. 11 XPS spectra of the typical elements on the worn balls after tribological test under $100 \mathrm{~N}$. 
as obtained using XPS analysis. Table 6 presents the contents of corresponding binding energies, obtained using theoretical calculations. Moreover, the peak area of every binding energy was obtained through peak fitting, and the percentage contents of corresponding bonds were estimated. As can be seen in Fig. 11, the $C$ element on the worn surface mainly exists in three forms: non-oxygenated ring carbon $(\mathrm{C}-\mathrm{C} / \mathrm{C}=\mathrm{C}, \sim 285 \mathrm{eV}$ ), hydroxyl and epoxy carbon (C-OH/C-O-C, $\sim 286 \mathrm{eV}$ ), and carboxyl carbon $(\mathrm{C}=\mathrm{O}, \sim 289 \mathrm{eV})$. In these forms, $\mathrm{C}-\mathrm{C} / \mathrm{C}=\mathrm{C}$ corresponded to the basic bond of the NCMs, the $\mathrm{C}-\mathrm{O}$ and $\mathrm{C}=\mathrm{O}$ bonds were the oxygen-containing functional groups in the NCMs (such as GO(1) and Oct-O-GO(1)), or were produced by the friction process when the fresh metal surface was exposed to emulsions and air. The $\mathrm{O}$ element was present as iron oxides (i.e., $\left.\mathrm{FeO}, \mathrm{FeOOH}, \mathrm{Fe}_{3} \mathrm{O}_{4}, \sim 530 \mathrm{eV}\right), \mathrm{C}=\mathrm{O}(\sim 531 \mathrm{eV})$, and $\mathrm{C}-\mathrm{OH} / \mathrm{C}-\mathrm{O}-\mathrm{C}(\sim 532 \mathrm{eV})$. The Fe element was present in the form of $\mathrm{Fe}\left(\mathrm{C}_{5} \mathrm{H}_{5}\right)_{2}(\sim 710 \mathrm{eV}), \mathrm{Fe}(\sim 720 \mathrm{eV})$, and iron oxides $(\sim 730 \mathrm{eV})[65,66]$. The presence of iron oxides and $\mathrm{Fe}\left(\mathrm{C}_{5} \mathrm{H}_{5}\right)_{2}$ indicated that the NCM emulsions had reacted with the metal surface and formed the tribochemical reaction film.

From the summary in Table 6, it can be seen that the compositions of the lubricating films formed by all the emulsions were similar; however, the content of each component was different. The ball surface lubricated with the Oct-O-GO(1) emulsion yielded the highest $\mathrm{O}-\mathrm{H} / \mathrm{C}=\mathrm{O}$ content, whereas that lubricated with $G$ emulsion was the lowest. As previously discussed, when the load was $100 \mathrm{~N}$, the average
$\mathrm{COF}$ and the surface wear rate of the friction pairs lubricated by the Oct-O-GO (1) emulsion were the lowest, whereas those of friction pairs lubricated by the $G$ emulsion were the highest. This suggested that the higher composition of $\mathrm{O}-\mathrm{H} / \mathrm{C}=\mathrm{O}$ on the worn surface contributed to the superior lubricating properties. Moreover, less iron oxides formed on the surface lubricated by Oct-O-GO(1), thus indicating that the surface was well protected by a thick layer of complex (organic and inorganic) tribochemical reaction film. On the surface lubricated by $G$ emulsion, the content of iron oxides was very high, which indicated that more iron had reacted, thus resulting in severe wear, as suggested in Table 4. It was speculated that because the alkyl chains on the GO edges increased the inter-distance between layers and weakened the inter-molecular forces, the interfacial strength during frictional sliding could be reduced, resulting in less friction. Moreover, after sliding, the well exposed oxygen-containing functional groups of the molecular structure would interact with the freshly exposed metal surfaces, quickly forming a protective lubricating film with high oxygen containing compounds. The results suggested that the different contents of the components in the lubricating film formed on the sliding surfaces were the main cause of the different tribological performances of the NCM emulsions. Furthermore, the alkyl and $\mathrm{O}-\mathrm{H} / \mathrm{C}=\mathrm{O}$ containing ingredients, in conjunction with the carbon residue, were beneficial to the lubrication performance.

Table 6 Element on worn balls lubricated with emulsions after tribological test under $100 \mathrm{~N}$ by XPS analysis.

\begin{tabular}{|c|c|c|c|c|c|c|c|c|c|}
\hline \multirow{2}{*}{$\begin{array}{c}\text { Element } \\
\text { Binding } \\
\text { energy }(\mathrm{eV})\end{array}$} & \multicolumn{3}{|c|}{$\mathrm{C} 1 \mathrm{~s}$} & \multicolumn{3}{|c|}{$\mathrm{O} 1 \mathrm{~s}$} & \multicolumn{3}{|c|}{$\mathrm{Fe} 2 \mathrm{p}$} \\
\hline & $\sim 285$ & $\sim 286$ & $\sim 289$ & $\sim 530$ & $\sim 531$ & $\sim 532$ & $\sim 710$ & $\sim 720$ & $\sim 730$ \\
\hline $\begin{array}{c}\text { Corresponding } \\
\text { bond content } \\
(\%)\end{array}$ & $\begin{array}{l}\mathrm{C}-\mathrm{C} \\
\mathrm{C}=\mathrm{C}\end{array}$ & $\begin{array}{c}\mathrm{C}-\mathrm{OH} \\
\mathrm{C}-\mathrm{O}-\mathrm{C}\end{array}$ & $\mathrm{C}=\mathrm{O}$ & $\begin{array}{c}\mathrm{FeO} \\
\mathrm{FeOOH} \\
\mathrm{Fe}_{2} \mathrm{O}_{3} \\
\mathrm{Fe}_{3} \mathrm{O}_{4}\end{array}$ & $\begin{array}{l}\mathrm{C}=\mathrm{O} \\
\mathrm{O}-\mathrm{H}\end{array}$ & $\begin{array}{c}\mathrm{C}-\mathrm{OH} \\
\mathrm{C}-\mathrm{O}-\mathrm{C}\end{array}$ & $\begin{array}{c}\mathrm{Fe} \\
\mathrm{Fe}\left(\mathrm{C}_{2} \mathrm{H}_{5}\right)_{2} \\
\mathrm{FeO} \\
\mathrm{FeOOH}\end{array}$ & $\mathrm{Fe}$ & $\mathrm{Fe}_{3} \mathrm{O}_{4}$ \\
\hline C60 emulsion & 79.59 & 10.98 & 9.43 & 35.03 & 51.29 & 13.68 & 28.44 & 28.45 & 42.22 \\
\hline $\begin{array}{l}\text { MWCNT } \\
\text { emulsion }\end{array}$ & 56.11 & 37.85 & 6.05 & 50.15 & 49.85 & - & 44.76 & 24.95 & 27.89 \\
\hline $\mathrm{G}$ emulsion & 42.28 & 46.38 & 11.34 & 66.47 & 9.21 & 24.32 & 65.98 & 26.94 & 7.07 \\
\hline $\mathrm{GO}(1)$ emulsion & 56.10 & 34.61 & 9.29 & 61.93 & 35.39 & - & 44.18 & 19.79 & 36.03 \\
\hline $\begin{array}{l}\text { Oct-O-GO(1) } \\
\text { emulsion }\end{array}$ & 46.50 & 41.37 & 12.13 & - & 96.15 & 3.85 & 35.11 & 52.18 & 10.68 \\
\hline
\end{tabular}




\section{Conclusion}

In this work, two types of GOs with different oxidation degrees $(\mathrm{GO}(1)$ and $\mathrm{GO}(2))$ were successfully prepared using the modified Hummers' method, and one n-octanol functionalized GO (Oct-O-GO(1)). Their structures were confirmed using FTIR spectroscopy, Raman spectroscopy, XRD, TGA, and SEM analysis. The tribological behaviors of five types of NCMs with different dimensions in an $\mathrm{O} / \mathrm{W}$ system, including zero dimensional C60, one-dimensional MWCNT, 2D $\mathrm{GO}$, n-octanol modified graphene oxide (Oct-O-GO), and 3D graphite were studied, and the following conclusions can be drawn:

(1) The stabilities indicated that all the NCMs can be well dispersed in the same oil-in-water system. Moreover, the prepared NCM emulsions exhibited good stabilities.

(2) The tribological tests revealed that the Oct-O$\mathrm{GO}(1)$ emulsion exhibited the best load-carrying capacity, in addition to the best friction-reducing and anti-wear properties.

(3) The lubrication mechanism was investigated using SEM-EDS, micro-Raman spectroscopy, and XPS. The results indicated that during frictional sliding, the ingredients in the emulsion can react with the freshly exposed metal surface and be absorbed by it, thus forming surface-active films to protect the surfaces from abrasion. Moreover, the ingredients containing alkyl and $\mathrm{O}-\mathrm{H} / \mathrm{C}=\mathrm{O}$, in addition to the carbon residue in the tribofilm generated on the meal surface, improved the lubrication performance.

\section{Acknowledgements}

The authors are grateful to the National Natural Science Foundation of China (Nos. 21703279, and 21506064), Shanghai Natural Science Foundation (No. 17ZR1442100) and the Shanghai Municipal "Science and Technology Innovation Action Plan" International Cooperation Project (No. 15540723600) for financial support.

Open Access: The articles published in this journal are distributed under the terms of the Creative Commons Attribution 4.0 International License (http:// creativecommons.org/licenses/by/4.0/), which permits unrestricted use, distribution, and reproduction in any medium, provided you give appropriate credit to the original author(s) and the source, provide a link to the Creative Commons license, and indicate if changes were made.

\section{References}

[1] Gupta B, Kumar N, Panda K, Melvin A A, Joshi S, Dash S, Tyagi A K. Effective noncovalent functionalization of Poly(ethylene glycol) to reduced graphene oxide nanosheets through $\gamma$-radiolysis for enhanced lubrication. J Phys Chem C 120(4): 2139-2148 (2016)

[2] Filleter T, McChesney J L, Bostwick A, Rotenberg E, Emtsev K V, Seyller T, Horn K, Bennewitz R. Friction and dissipation in epitaxial graphene films. Phys Rev Lett 102(8): 086102 (2009)

[3] Filleter T, Bennewitz R. Structural and frictional properties of graphene films on $\mathrm{SiC}(0001)$ studied by atomic force microscopy. Phys Rev B 81(15):155412 (2010)

[4] Grierson D S, Carpick R W. Nanotribology of carbon-based materials. Nanotoday 2(5): 12-21 (2007)

[5] Dienwiebel M, Verhoeven G S, Pradeep N, Frenken J W M, Heimberg J A, Zandbergen H W. Superlubricity of graphite. Phys Rev Lett 92(12): 126101 (2004)

[6] Konicek A R, Grierson D S, Gilbert P U P A, Sawyer W G, Sumant A V, Carpick R W. Origin of ultralow friction and wear in ultrananocrystalline diamond. Phys Rev Lett 100(23): 235502 (2008)

[7] Gupta B, Panda K, Kumar N, Melvin A A, Dash S, Tyagi A K. Chemically grafted graphite nanosheets dispersed in poly(ethylene-glycol) by $\gamma$-radiolysis for enhanced lubrication. RSC Adv 5(66): 53766-53775 (2015)

[8] Yu B, Liu Z L, Ma C B, Sun J J, Liu W M, Zhou F. Ionic liquid modified multi-walled carbon nanotubes as lubricant additive. Tribol Int 81: 38-42 (2015)

[9] Santhosh V, Voggu R, Chaturbedy P, Ganapathy R, Rao C N R. Mechanical properties of $\mathrm{C}_{60}$ thin films at the air-water interface. Carbon 96: 1-5 (2016)

[10] Wu K Y, Qiang L, Gong Z B, Zhao G R, Gao K X, Zhang B, Zhang J Y. The tribological performance of fullerene-like hydrogenated carbon films under ionic liquid lubrication. Surf Interface Anal 47(9): 903-910 (2015)

[11] Michinobu T, Nakanishi T, Hill J P, Funahashi M, Ariga $\mathrm{K}$. Room temperature liquid fullerenes: An uncommon morphology of $\mathrm{C}_{60}$ derivatives. $J$ Am Chem Soc 128(32): 10384-10385 (2006)

[12] Hisakado T, Kanno A. Effects of fullerene $C_{60}$ on the friction and wear characteristics of ceramics in ethanol. Tribol Int 32(7): 413-420 (1999)

[13] Jiang G C, Yang Y Y. Preparation and tribology properties of 
water-soluble fullerene derivative nanoball. Arabian $J$ Chem 10(S1): S870-S876 (2017)

[14] Lei H, Guan W C, Luo J B. Tribological behavior of fullerene-styrene sulfonic acid copolymer as water-based lubricant additive. Wear 252(3-4): 345-350 (2002)

[15] Liu B Y, Li H G. Alkylated fullerene as lubricant additive in paraffin oil for steel/steel contacts. Fuller, Nanotub Carbon Nanostr 24(11): 712-719 (2016)

[16] Huang W T, Wu D H, Lin S P, Liu W S. A combined minimum quantity lubrication and MWCNT cutting fluid approach for SKD 11 end milling. Int J Adv Manuf Technol 84(5-8): 1697-1704 (2016)

[17] Marquis F D S, Chibante L P F. Improving the heat transfer of nanofluids and nanolubricants with carbon nanotubes. JOM 57(12): 32-43 (2005)

[18] Khalil W, Mohamed A, Bayoumi M, Osman T A. Tribological properties of dispersed carbon nanotubes in lubricant. Fuller, Nanotub Carbon Nanostr 24(7): 479-485 (2016)

[19] Muzakkir S M, Lijesh K P, Hirani H. Influence of surfactants on tribological behaviors of MWCNTs (multi-walled carbon nano-tubes). Tribol - Mater, Surf Interfaces 10(2): 74-81 (2016)

[20] Buckley D H, Brainar W A. Friction and wear of metals in contact with pyrolytic graphite. Carbon 13(6): 501-508 (1975)

[21] Ruan J A, Bhushan B. Frictional behavior of highly oriented pyrolytic graphite. J Appl Phys 76(12): 8117 (1994)

[22] Liao Y, Pourzal R, Wimmer M A, Jacobs J J, Fischer A, Marks L D. Graphitic tribological layers in metal-on-metal hip replacements. Science 334(6063): 1687-1690 (2011)

[23] Erdemir A, Ramirez G, Eryilmaz O L, Narayanan B, Liao Y F, Kamath G, Sankaranarayanan S K R S. Carbon-based tribofilms from lubricating oils. Nature 536(7614): 67-71 (2016)

[24] Dreyer D R, Park S, Bielawski C W, Ruof R S. The chemistry of graphene oxide. Chem Soc Rev 39(1): 228-240 (2010)

[25] Chen T D, Xia Y Q, Jia Z F, Liu Z L, Zhang H B. Synthesis, characterization, and tribological behavior of oleic acid capped graphene oxide. J Nanomater 2014: 654145 (2014)

[26] Suñer S, Joffe R, Tipper J L, Emami N. Ultra high molecular weight polyethylene/graphene oxide nanocomposites: Thermal, mechanical and wettability characterisation. Compos Part B: Eng 78: 185-191 (2015)

[27] Pan B L, Zhang S P, Li W Z, Zhao J, Liu J L, Zhang Y Q, Zhang Y Z. Tribological and mechanical investigation of MC nylon reinforced by modified graphene oxide. Wear 294-295: 395-401 (2012)

[28] Kim H J, Shin D G, Kim D E. Frictional behavior between silicon and steel coated with graphene oxide in dry sliding and water lubrication conditions. Int J Precis Eng Manuf-Green Technol 3(1): 91-97 (2016)

[29] Hu Y S, Ma H B, Liu W, Lin Q Q, Liu B. Preparation and investigation of the microtribological properties of graphene oxide and graphene films via electrostatic layer-by-layer self-assembly. J Nanomater 2015: 282369 (2015)

[30] Elomaa O, Singh V K, Iyer A, Hakala T J, Koskinen J. Graphene oxide in water lubrication on diamond-like carbon vs. stainless steel high-load contacts. Diamond Relat Mater 52: 43-48 (2015)

[31] Li J C, Zeng X Q, Ren T H, van der Heide E. The preparation of graphene oxide and its derivatives and their application in bio-tribological systems. Lubricants 2(3): 137-161 (2014)

[32] Liu Y H, Wang X K, Pan G S, Luo J B. A comparative study between graphene oxide and diamond nanoparticles as water-based lubricating additives. Sci China Technol Sci 56(1): 152-157 (2013)

[33] Chen Z, Liu Y H, Luo J B. Tribological properties of few-layer graphene oxide sheets as oil-based lubricant additives. Chin J Mechan Eng 29(2): 439-444 (2016)

[34] Cheng Z L, Li W, Wu P R, Liu Z. A strategy for preparing modified graphene oxide with good dispersibility and transparency in oil. Ind Eng Chem Res 56(19): 5527-5534 (2017)

[35] He A S, Huang S Q, Yun J H, Jiang Z Y, Stokes J R, Jiao S H, Wang L Z, Huang H. Tribological characteristics of aqueous graphene oxide, graphitic carbon nitride, and their mixed suspensions. Tribol Lett 66(1): 42 (2018)

[36] Mungse H P, Kumar N, Khatri O P. Synthesis, dispersion and lubrication potential of basal plane functionalized alkylated graphene nanosheets. $R S C A d v$ 5(32): 25565-25571 (2015)

[37] Kinoshita H, Nishina Y, Alias A A, Fujii M. Tribological properties of monolayer graphene oxide sheets as waterbased lubricant additives. Carbon 66:720-723 (2014)

[38] Khare V, Pham M Q, Kumari N, Yoon H S, Kim C S, Park J I L, Ahn S H. Graphene-ionic liquid based hybrid nanomaterials as novel lubricant for low friction and wear. ACS Appl Mater Interfaces 5(10): 4063-4075 (2013)

[39] Chen J, Li Y R, Huang L, Li C, Shi G Q. High-yield preparation of graphene oxide from small graphite flakes via an improved Hummers method with a simple purification process. Carbon 81: 826-834 (2015)

[40] Marcano D C, Kosynkin D V, Berlin J M, Sinitskii A, Sun Z Z, Slesarev A, Alemany L B, Lu W, Tour J M. Improved synthesis of graphene oxide. ACS Nano 4(8): 4806-4814 (2010)

[41] Wang S S, Wang J, Zhang W F, Ji J Y, Li Y, Zhang G L, Zhang F B, Fan X B. Ethylenediamine modified graphene and its chemically responsive supramolecular hydrogels. Ind 
Eng Chem Res 53(33): 13205-13209 (2014)

[42] Lin Y, Chen Y Z, Zeng Z K, Zhu J R, Wei Y, Li F C, Liu L. Effect of $\mathrm{ZnO}$ nanoparticles doped graphene on static and dynamic mechanical properties of natural rubber composites. Compos Part A: Appl Sci Manuf 70: 35-44 (2015)

[43] Samanta S, Singh S, Sahoo R R. Simultaneous chemical reduction and surface functionalization of graphene oxide for efficient lubrication of steel-steel contact. RSC Adv 5(76): 61888-61899 (2015)

[44] Abbasi Z, Haghighi M, Fatehifar E, Saedy S. Synthesis and physicochemical characterizations of nanostructured $\mathrm{Pt} / \mathrm{Al}_{2} \mathrm{O}_{3^{-}}$ $\mathrm{CeO}_{2}$ catalysts for total oxidation of VOCs. J Hazard Mater 186(2-3): 1445-1454 (2011)

[45] Garg K, Shanmugam R, Ramamurthy P C. New covalent hybrids of graphene oxide with core modified and -expanded porphyrins: Synthesis, characterisation and their non linear optical properties. Carbon 122: 307-318 (2017)

[46] McAllister M J, Li J L, Adamson D H, Schniepp H C, Abdala A A, Liu J, Herrera-Alonso M, Milius D L, Car R, Prud'homme R K, et al. Single sheet functionalized graphene by oxidation and thermal expansion of graphite. Chem Mater 19(18): 4396-4404(2007)

[47] Lerf A, He H Y, Forster M, Klinowski J. Structure of graphite oxide revisited. J Phys Chem B 102(23): 4477-4482 (1998)

[48] Wang G C, Yang Z Y, Li X W, Li C Z. Synthesis of poly(aniline-co-o-anisidine)-intercalated graphite oxide composite by delamination/reassembling method. Carbon $\mathbf{4 3}(12)$ : 2564-2570 (2005)

[49] Mondal T, Basak S, Bhowmick A K. Ionic liquid modification of graphene oxide and its role towards controlling the porosity, and mechanical robustness of polyurethane foam. Polymer 127: 106-118 (2017)

[50] Stankovich S, Dikin D A, Piner R D, Kohlhaas K A, Kleinhammes A, Jia Y Y, Wu Y, Nguyen S T, Ruoff R S. Synthesis of graphene-based nanosheets via chemical reduction of exfoliated graphite oxide. Carbon 45(7): 1558-1565 (2007)

[51] Bokobza L, Bruneel J L, Couzi M. Raman spectra of carbon-based materials (from graphite to carbon black) and of some silicone composites. C 1(1): 77-94 (2015)

[52] Zhou P, Rao A M, Wang K A, Robertson J D, Eloi C, Meier M S, Ren S L, Bi X X, Eklund P C, Dresselhaus M S. Photo-assisted structural transition and oxygen diffusion in solid $\mathrm{C}_{60}$ films. Appl Phys Lett 60(23): 2871-2873 (1992)

[53] Nizam R, Sehban M M, Parveen S. Raman spectroscopy of fullerene-60. Int J Emerg Technol Adv Eng 5(2): 319-323 (2015)

[54] Santangelo S, Messina G, Faggio G, Lanza M, Milone C. Evaluation of crystalline perfection degree of multi-walled carbon nanotubes: Correlations between thermal kinetic analysis and micro-Raman spectroscopy. J Raman Spectrosc 42(4): 593-602 (2011)

[55] Nikiel L, Jagodzinski P W. Raman spectroscopic characterization of graphites: A re-evaluation of spectra/ structure correlation. Carbon 31(8): 1313-1317 (1993)

[56] Tuinstra F, Koenig J L. Raman spectrum of graphite. $J$ Chem Phy 53(3): 1126-1130 (1970)

[57] Frolova L V, Magedov I V, Harper A, Jha S K, Ovezmyradov M, Chandler G, Garcia J, Bethke D, Shaner E A, Vasiliev I, et al. Tetracyanoethylene oxide-functionalized graphene and graphite characterized by Raman and Auger spectroscopy. Carbon 81: 216-222 (2015)

[58] Ganguly A, Sharma S, Papakonstantinou P, Hamilton J. Probing the thermal deoxygenation of graphene oxide using high-resolution in situ X-ray-based spectroscopies. J Phys Chem C 115(34): 17009-17019 (2011)

[59] Botas C, Álvarez P, Blanco P, Granda M, Blanco C, Santamaría R, Romasanta L J, Verdejo R, López-Manchado M A, Menéndez R. Graphene materials with different structures prepared from the same graphite by the Hummers and Brodie methods. Carbon 65: 156-164 (2013)

[60] Mattevi C, Eda G, Agnoli S, Miller S, Mkhoyan K A, Celik O, Mastrogiovanni D, Granozzi G, Garfunkel E, Chhowalla M. Evolution of electrical, chemical, and structural properties of transparent and conducting chemically derived graphene thin films. Adv Funct Mater 19(16): 2577-2583 (2009)

[61] Barnes H A. A Handbook of Elementary Rheology. Wales (UK): University of Wales, 2000.

[62] Chen Y, Liu W Y, Wang X T. Statistical characteristics of raman shift of petroleum components I: Alkanes and aromatic hydrocarbons. Spectrosc Spect Anal 36(8): 2510-2517 (2016).

[63] Zakhidov E A, Zakhidova M A, Kokhkharov A M, Nematov S K, Nusretov R A, Kuvondikov V O, Saparbaev A A. Raman spectroscopy of the interface between a thin nanostructured $\mathrm{ZnO}$ film and fullerene $\mathrm{C}_{60}$. Opt Spectrosc 122(4): 607-614 (2017)

[64] Ho M, Pemberton J E. Alkyl chain conformation of octadecylsilane stationary phases by Raman spectroscopy. 1. Temperature dependence. Anal Chem 70(23): 4915-4920 (1998)

[65] Cai M R, Liang Y M, Zhou F, Liu W M. A novel imidazolium salt with antioxidation and anticorrosion dual functionalities as the additive in poly (ethylene glycol) for steel/steel contacts. Wear 306(1-2): 197-208 (2013)

[66] Yu Q L, Fan M J, Li D M, Song Z H, Cai M R, Zhou F, Liu W M. Thermoreversible gel lubricants through universal supramolecular assembly of a nonionic surfactant in a variety of base lubricating liquids. ACS Appl Mater Interfaces 6(18): 15783-15794 (2014) 


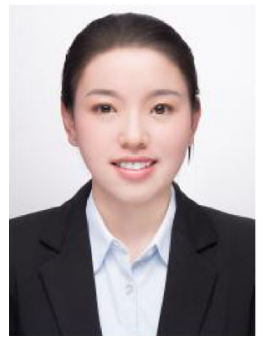

Hongmei YANG. She received her master degree in organic chemistry from East China Normal University in 2014. Then, she worked at Shanghai Runcong Chemical Technology Co., Ltd. during 2014-2015 as technical manager on lubricant technology.

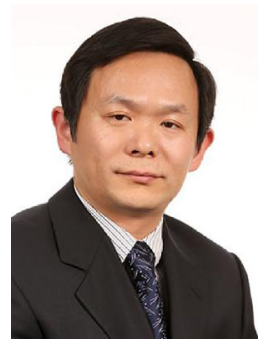

Jiusheng LI. He received his $\mathrm{PhD}$ degree in material science from Shanghai Jiao Tong University in 2002. Then, he worked at Lanzhou Lubricating Oil R\&D Center of Petrochina as Deputy Director during 2002-2012. His current position is

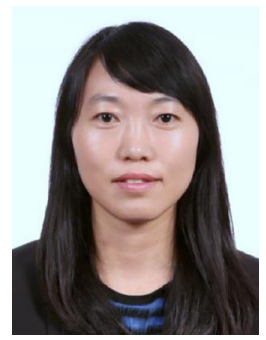

Xiangqiong ZENG. She received her master degree in applied chemistry in 2003 and PhD degree in material science in 2006 from Shanghai Jiao Tong University. Then, she worked at Johnson \& Johnson consumer group during 2006-2010 as staff scientist on skin care technology. From 2011-2015, she was appointed as a tenure track assistant professor at the University of Twente, working on skin tribology. Currently, she is a full
Currently, she is studying for a doctorate in organic chemistry from Shanghai Advanced Research Institute, Chinese Academy of Sciences. Her research fields include the synthesis and evaluation of lubricating additives, development of oil formulations, and construction of graphene oxide based Pickering emulsions and their tribological behaviors.

a professor and the director of Green Chemical Engineering Technology Centre in Shanghai Advanced Research Institute, Chinese Academy of Sciences. His research areas cover development of lubricating additives and lubricant formulation, as well as research on lubricating mechanisms.

professor at Shanghai Advanced Research Institute, Chinese Academy of Sciences. Her research interests are functional interface materials for biotribology and aqueous lubrication, including active control of friction and wear by surface and interface design of skin contacting materials and medical devices, by test methodology development with the design of instrument and bio-inspired human tissue model, and by additive and emulsion development for aqueous lubrication. 